\section{The Confidential Inquiry comes of age}

\author{
CHRIS THOMPSON
}

The recent publication of the first full report of the National Confidential Inquiry into Homicides and Suicides by People with a Mental Illness is the final stage in a process of maturation that has taken almost a decade. Set up in 1991 under the auspices of the Royal College of Psychiatrists, it was funded by the Department of Health in an attempt to ascertain the facts about the number of homicides relating to "failures of community care'. Although homicides were politically sensitive, the vastly greater numbers of suicides among the mentally ill, and their inclusion in the Health of the Nation targets, made it imperative to include suicide in the remit.

\section{EARLY DAYS}

In the early period, the Inquiry was carefully nurtured by the first director, Dr William Boyd. His main task was to ensure that psychiatrists had confidence and some sense of ownership in the process of the Inquiry. The most crucial feature was the confidentiality of their reports. In this first phase psychiatrists were asked to notify the Inquiry of any deaths in their service, so a lack of confidence in the Inquiry would have led to low levels of reporting and potentially biased data.

Much time was spent in scientific presentations to explain the purpose and procedures of the Inquiry. But what quickly emerged was the degree of distress that was often felt by many psychiatrists at the loss of a patient, and this needed careful and sensitive handling by Dr Boyd.

Despite these personal efforts the method of case ascertainment of suicides (through consultant psychiatrists) was the main problem for the first Inquiry. In the end, few of the known total number of suicides were reported. The homicides, on the other hand, were obtained through the Home Office and were therefore a more systematic, yet still incomplete, sample. This, rather than political pressure, was the main reason that the early period of the Inquiry ended with a report on homicide alone (Boyd, 1994). Few firm recommendations could be made on these preliminary data, but already poor compliance was becoming obvious as a factor in many of the incidents. A supportive comment regarding forthcoming legislation on powers of supervised discharge was included. Several methodological changes were recommended and, with this, the Inquiry was ready for its next developmental stage.

\section{THE MIDDLE PERIOD}

This came about with the retirement of Dr Boyd soon after the preliminary report. The decision was made to seek tenders to run the Inquiry from academic departments. As a result it moved to its new home at the University of Manchester, under the directorship of Professor Appleby. The Royal College, however, remained actively involved and a new steering committee, under my chairmanship, was constituted to reflect two new facets of the Inquiry's work. A full range of mental health disciplines was included because the data collection was now to be through multi-disciplinary case review. Representatives of public health were also included because case ascertainment of suicide was now to come from public health directors. Furthermore, the health departments of Wales, Scotland and Northern Ireland began to contribute both finance and data to the project and it became a genuinely national inquiry.

These changes in structure and methodology have not diminished the commitment of the profession, which has increased steadily over the years. Currently $92 \%$ of all questionnaires sent to psychiatrists and their teams are successfully completed and returned.

The next step was the publication of a progress report in 1997 as required by the new government and the Department of

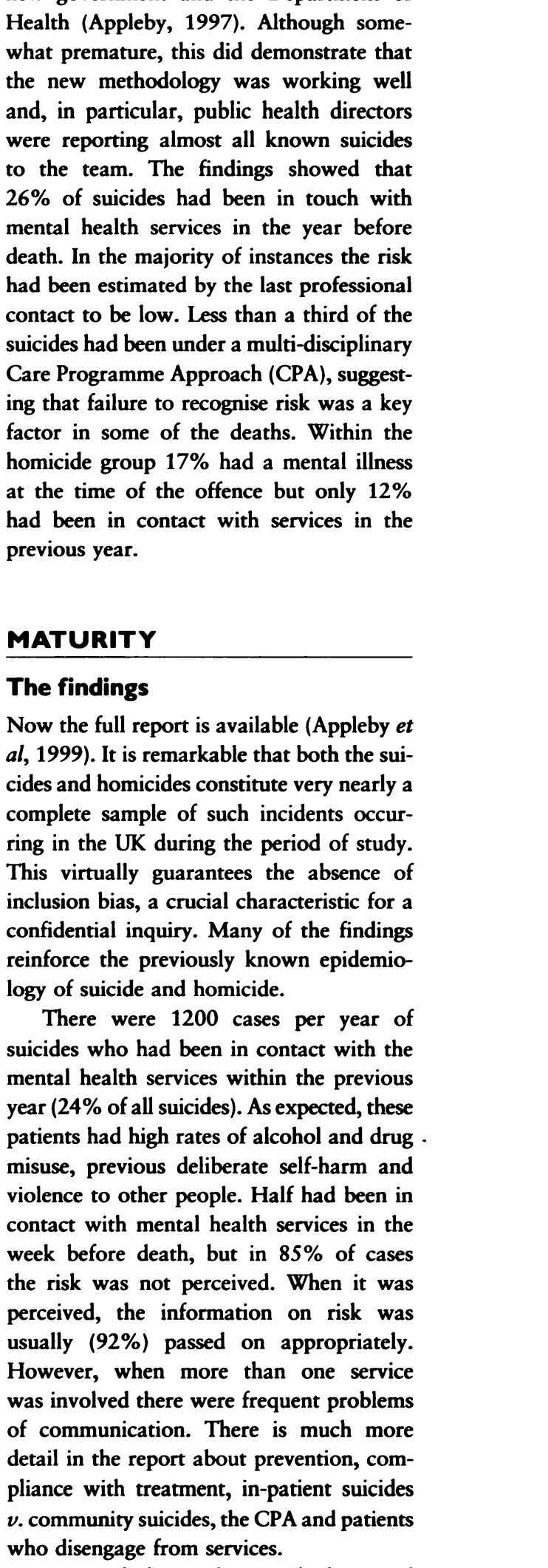

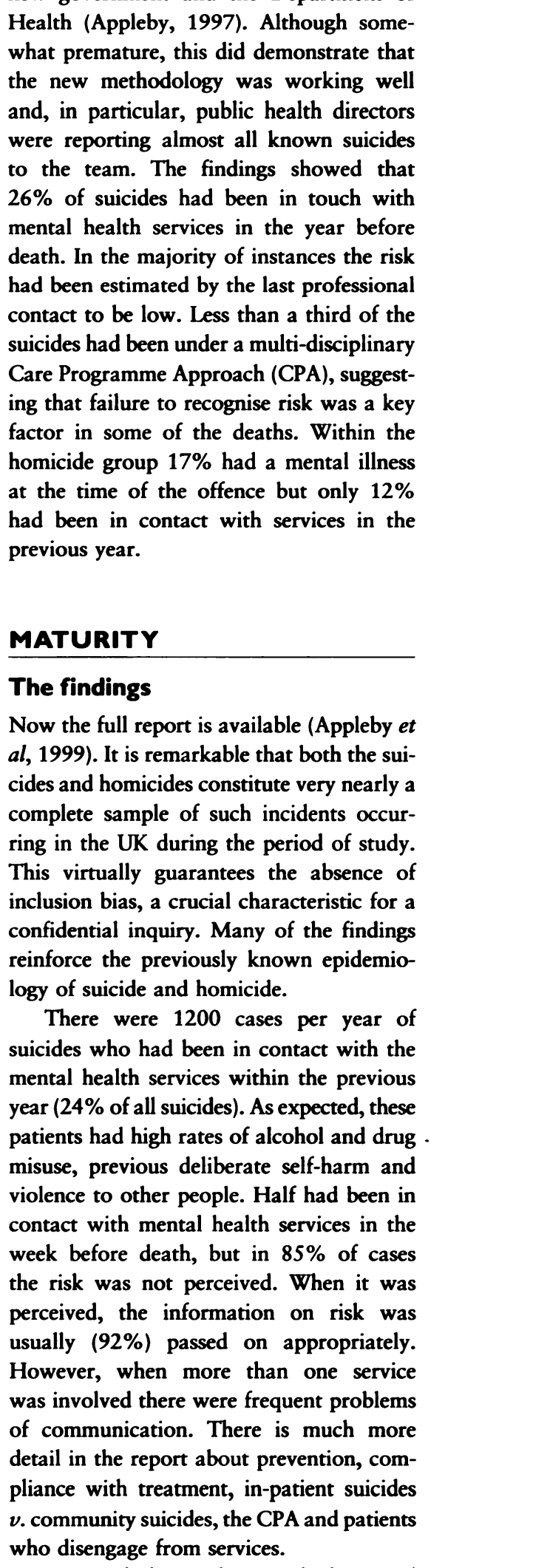

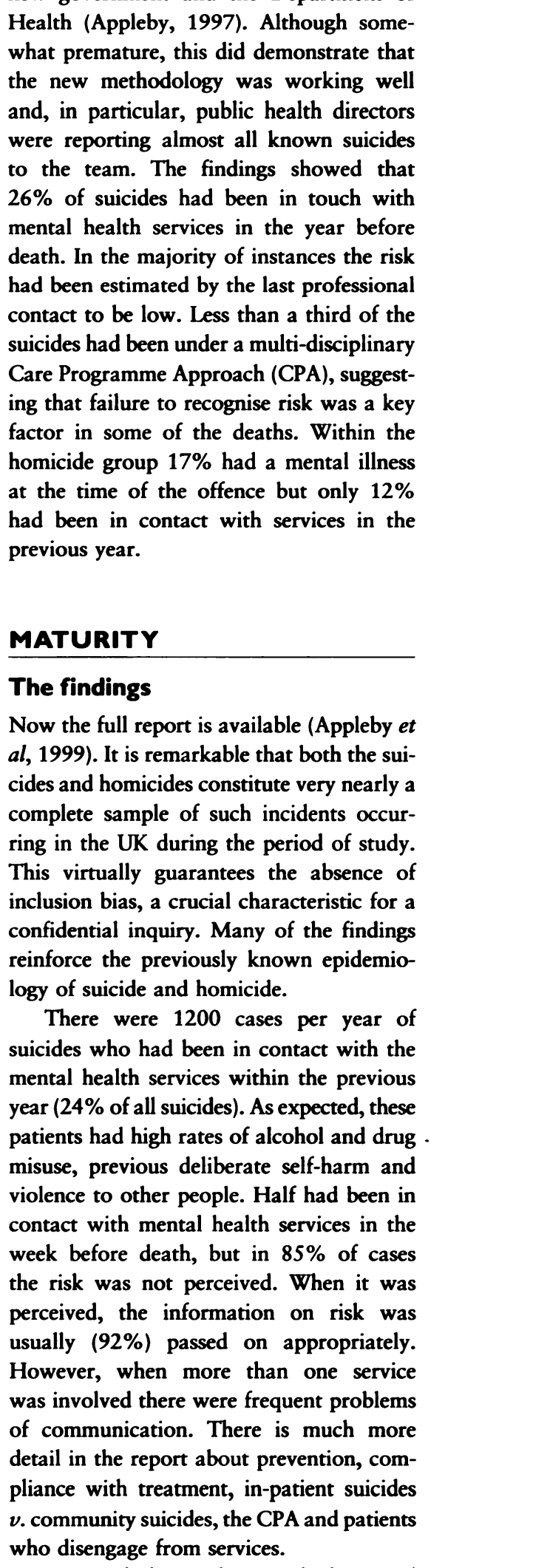

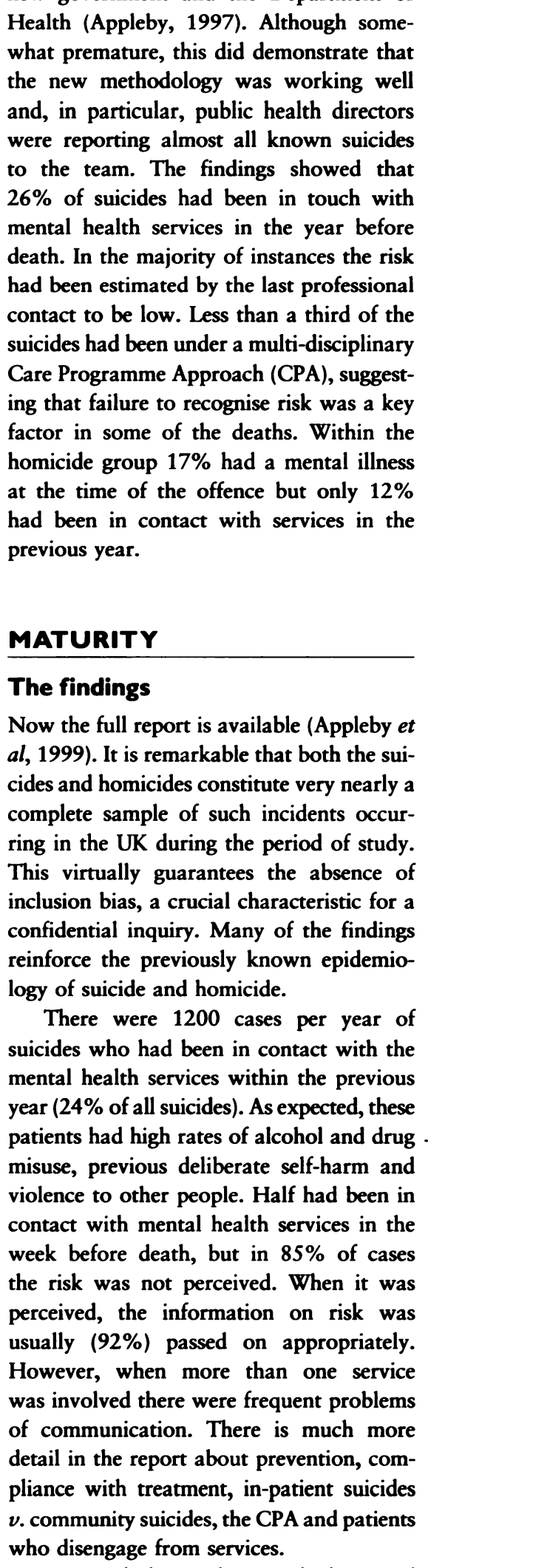

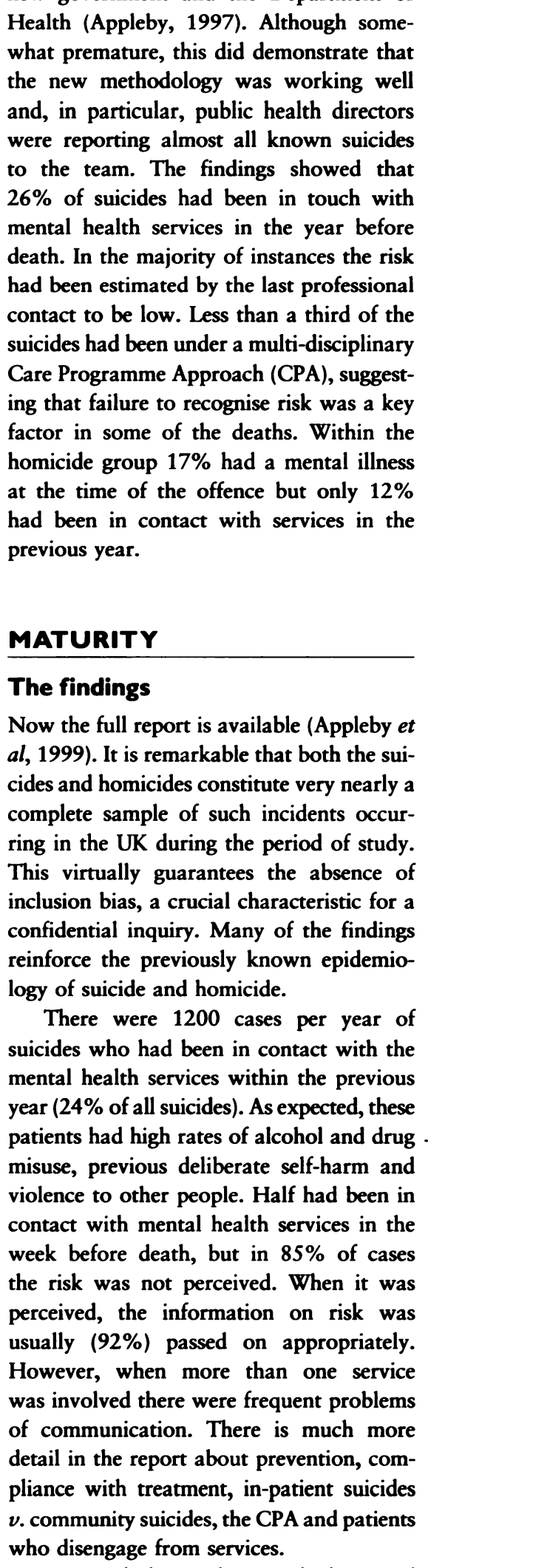

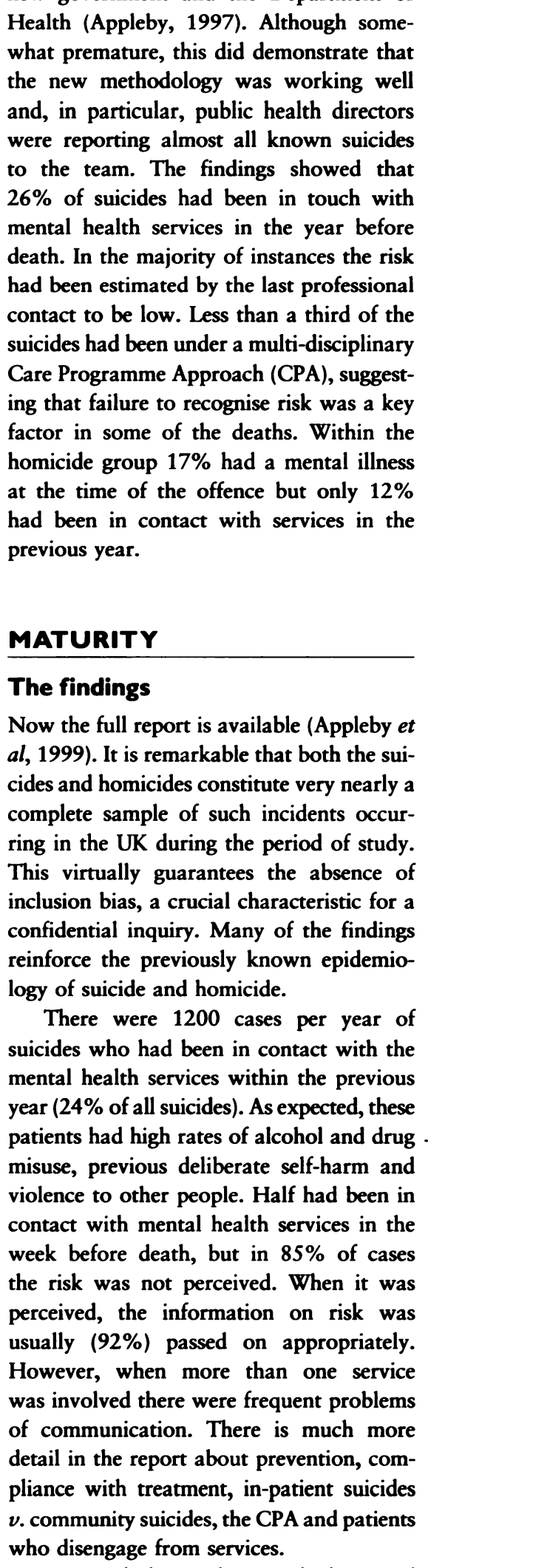

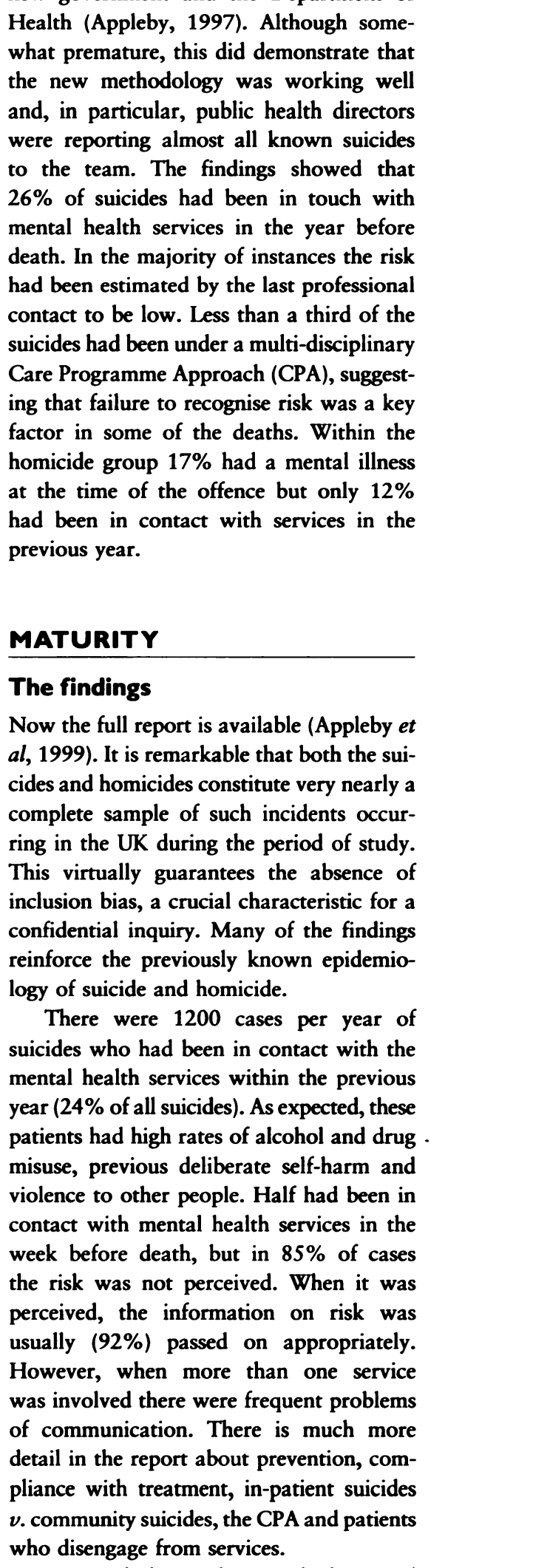

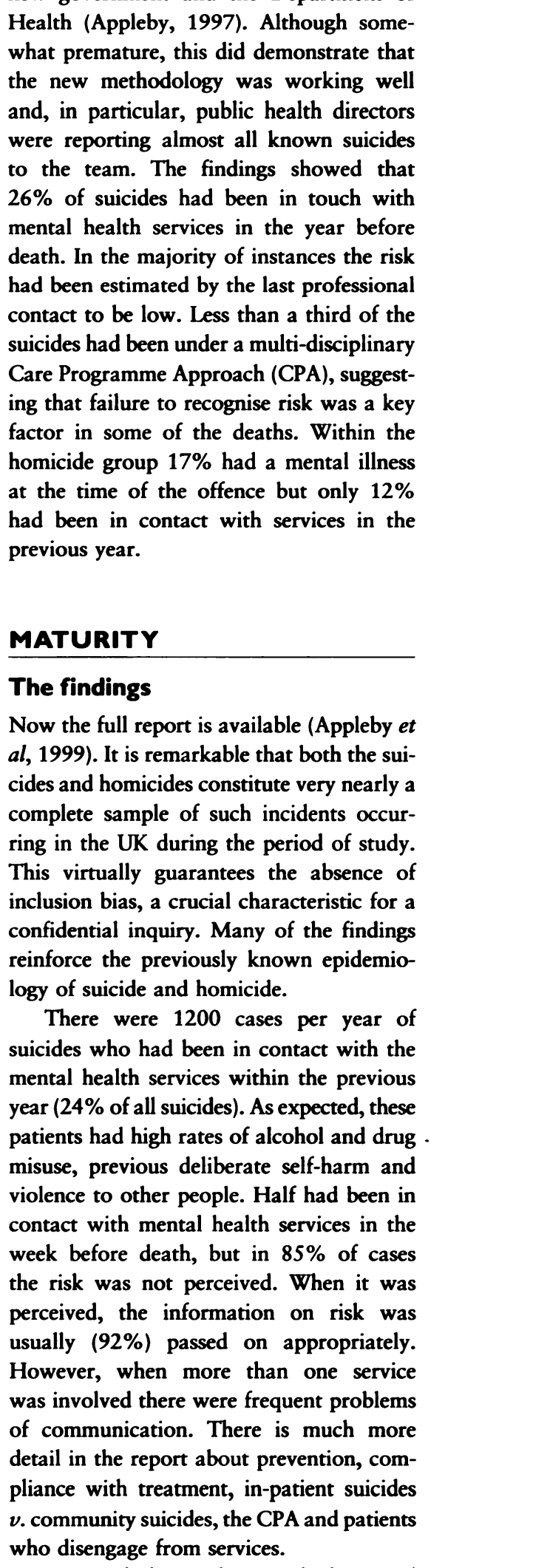

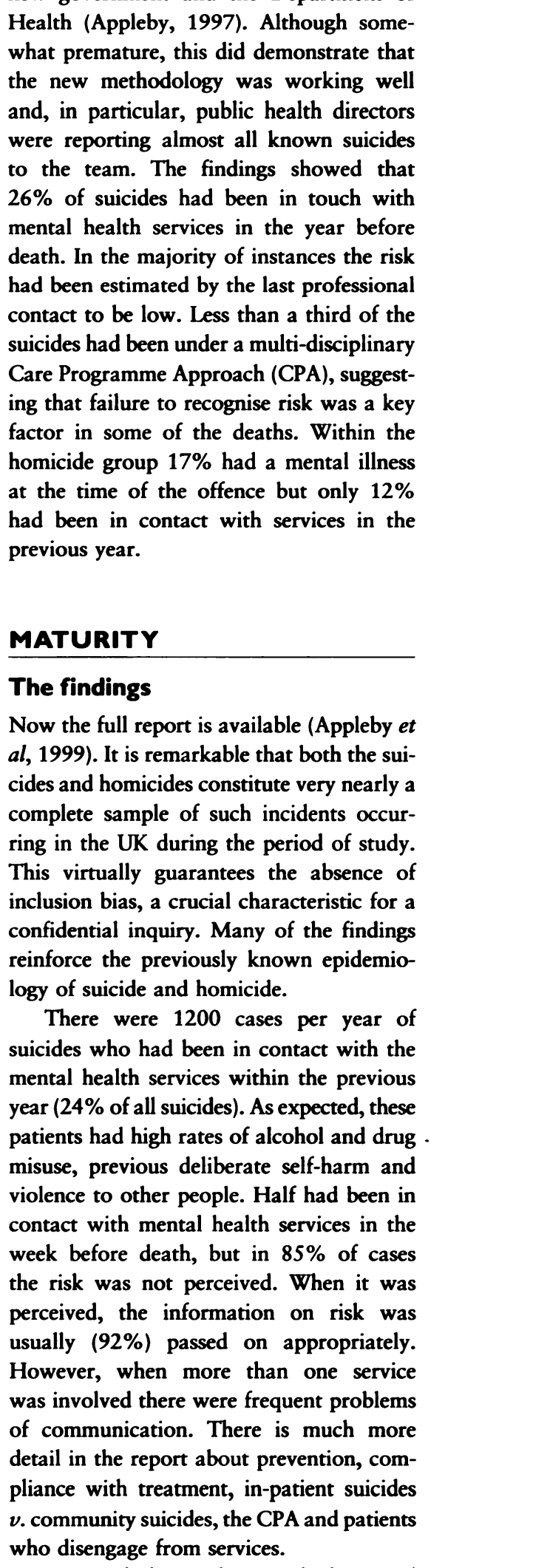

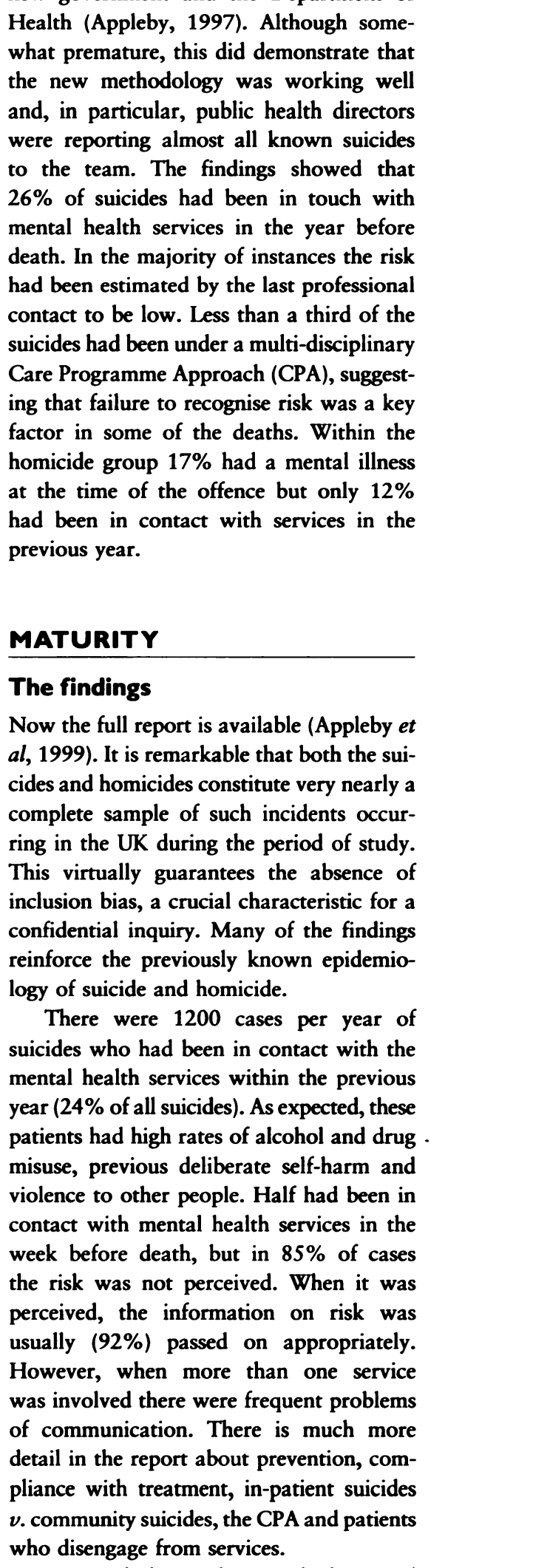

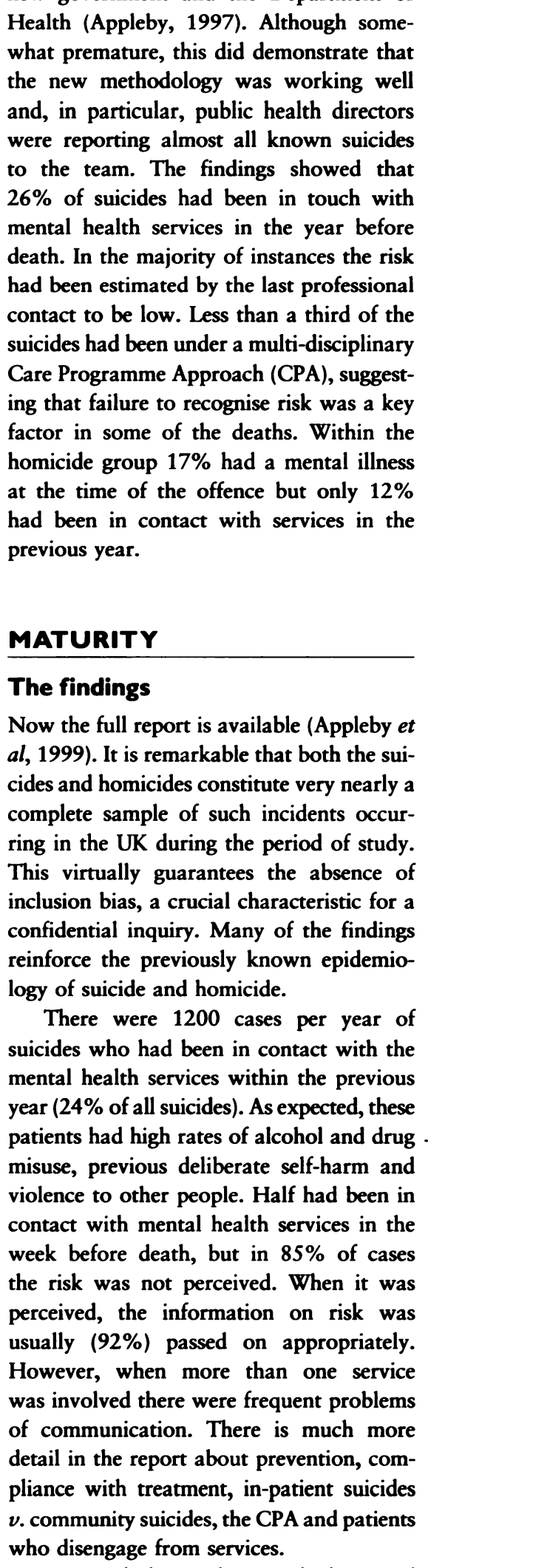

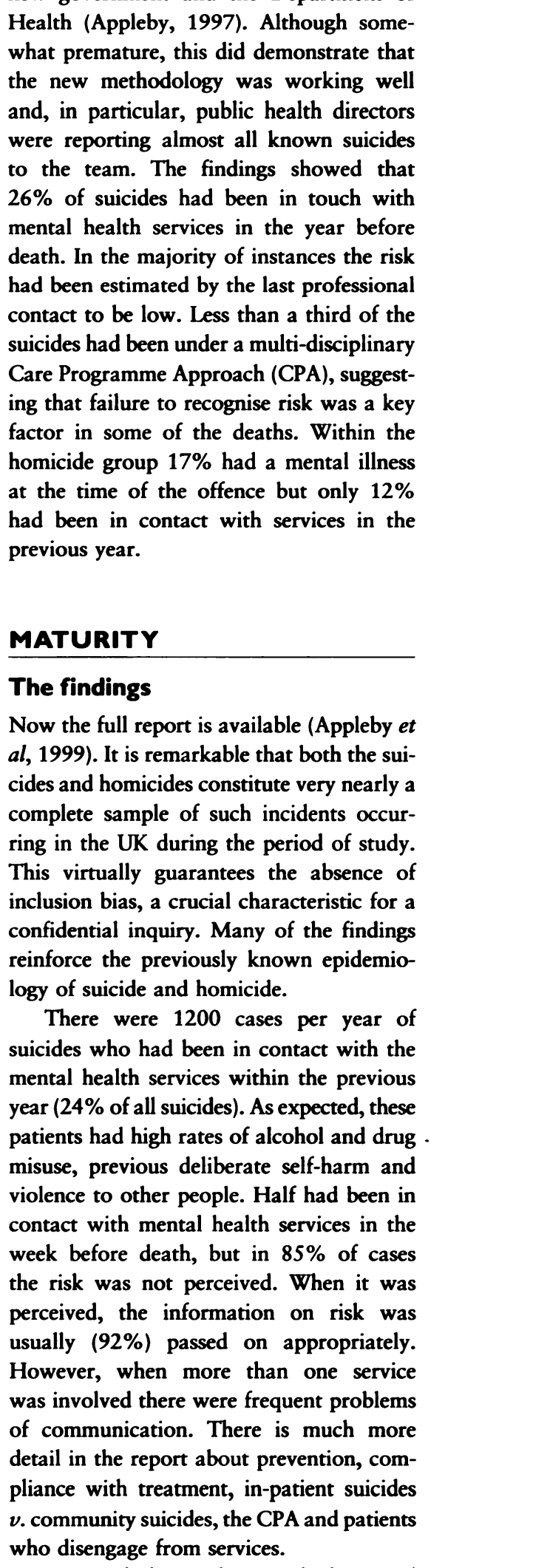

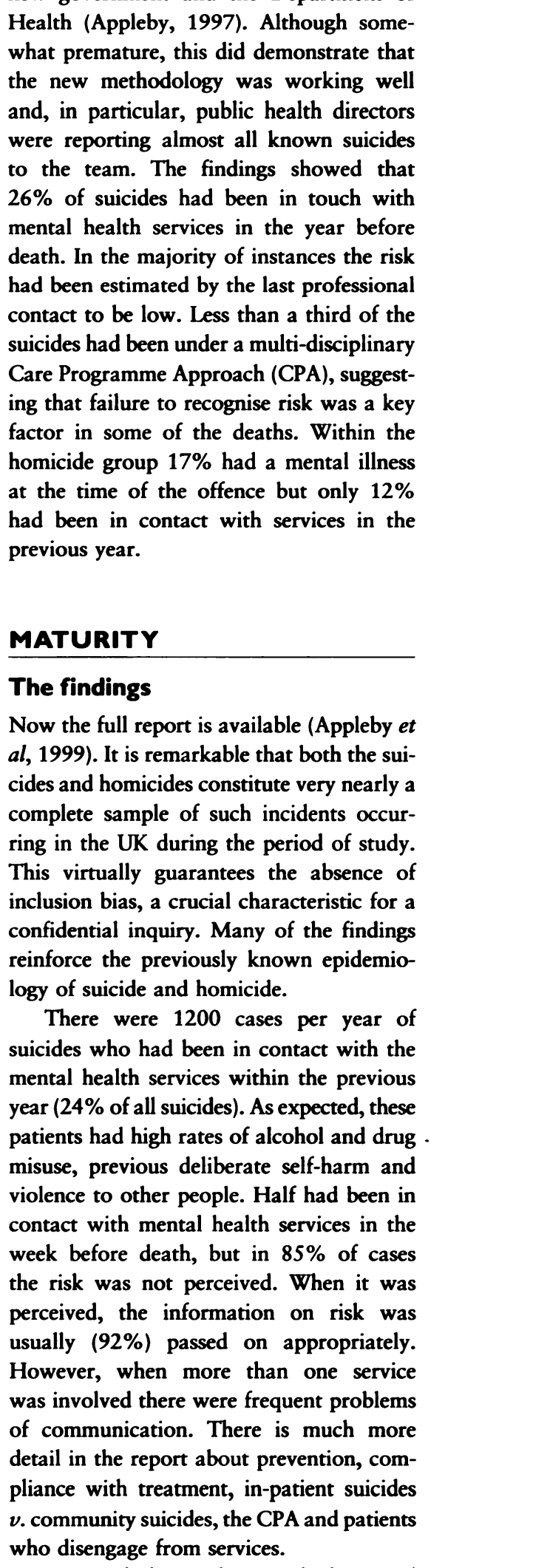

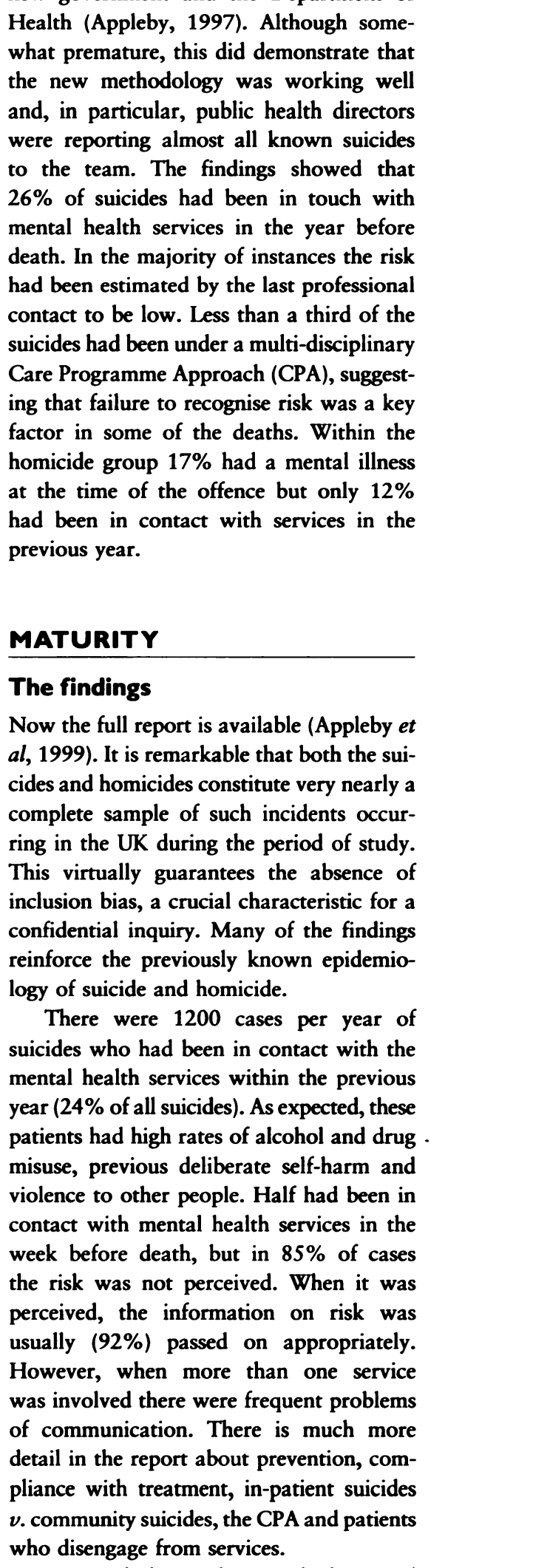

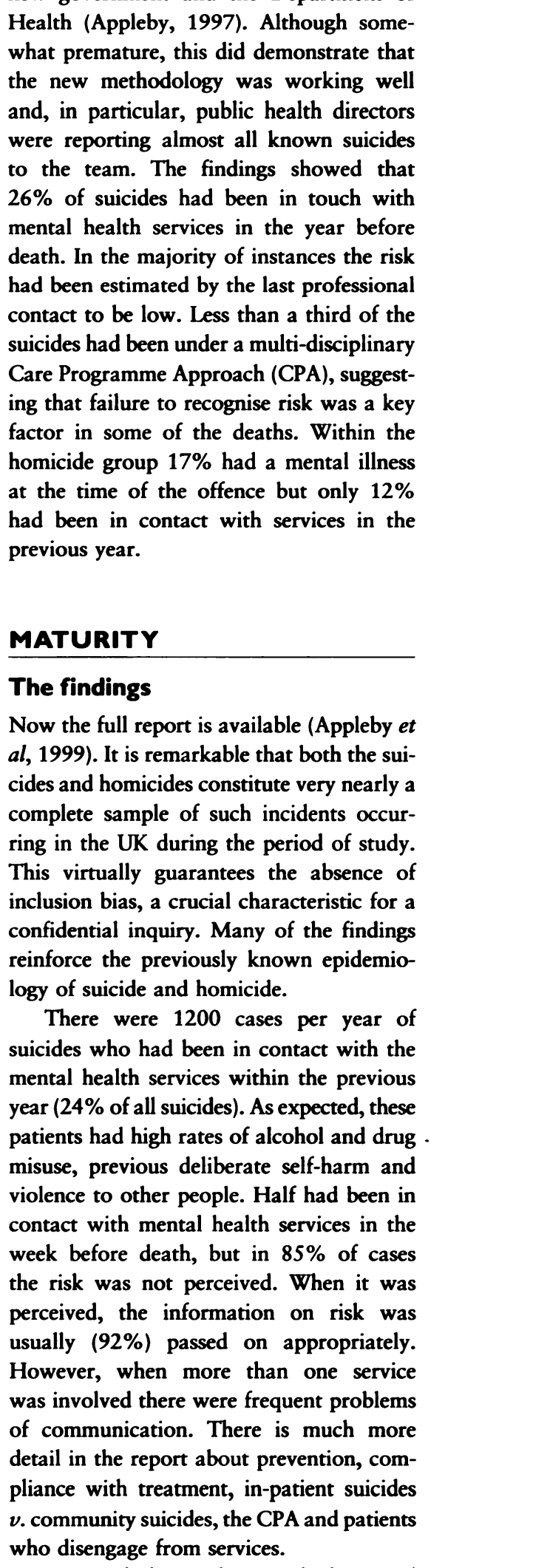

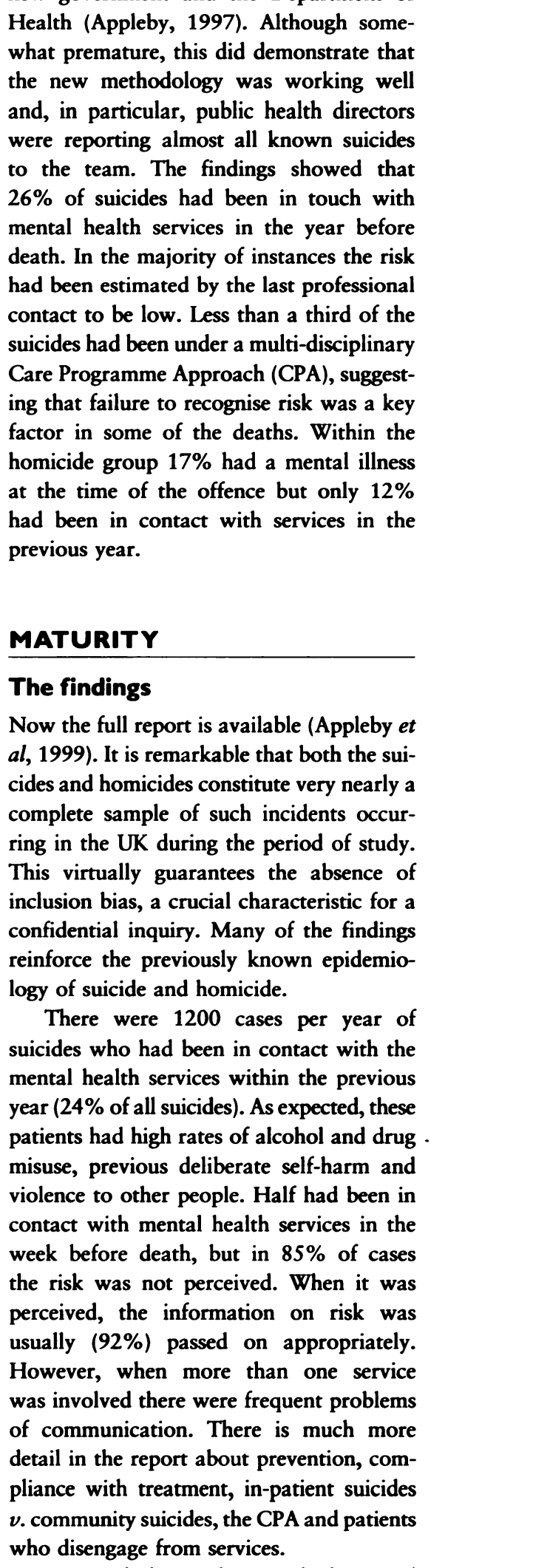

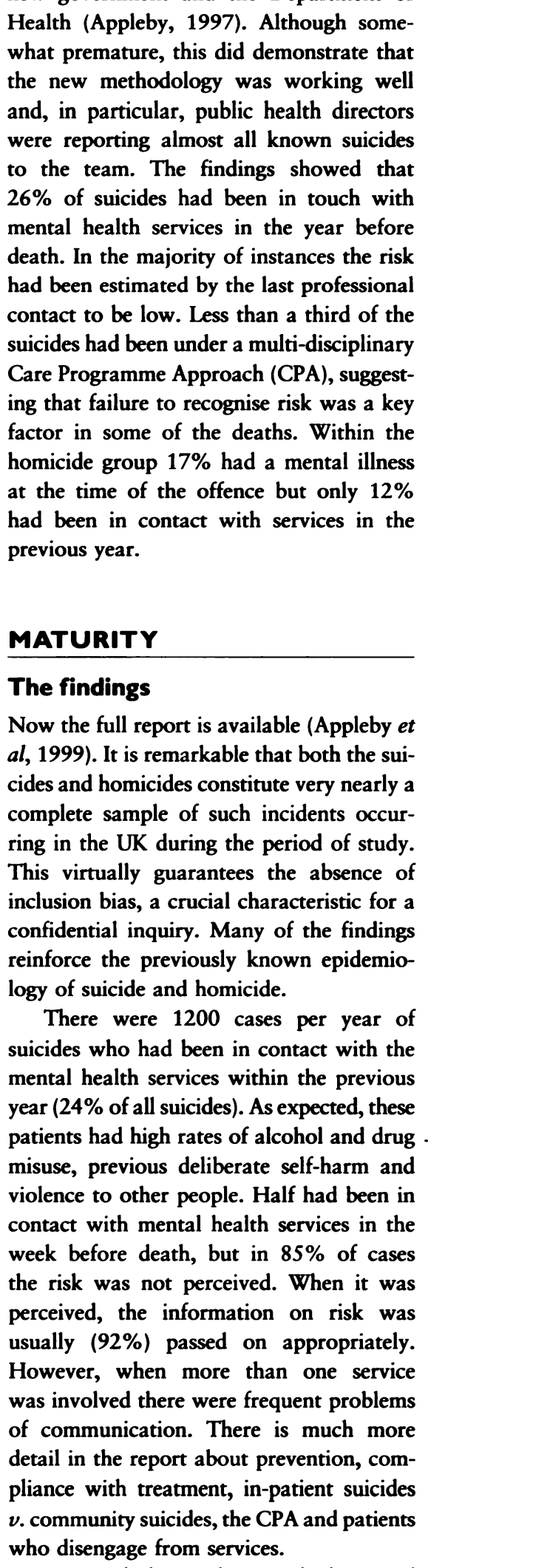

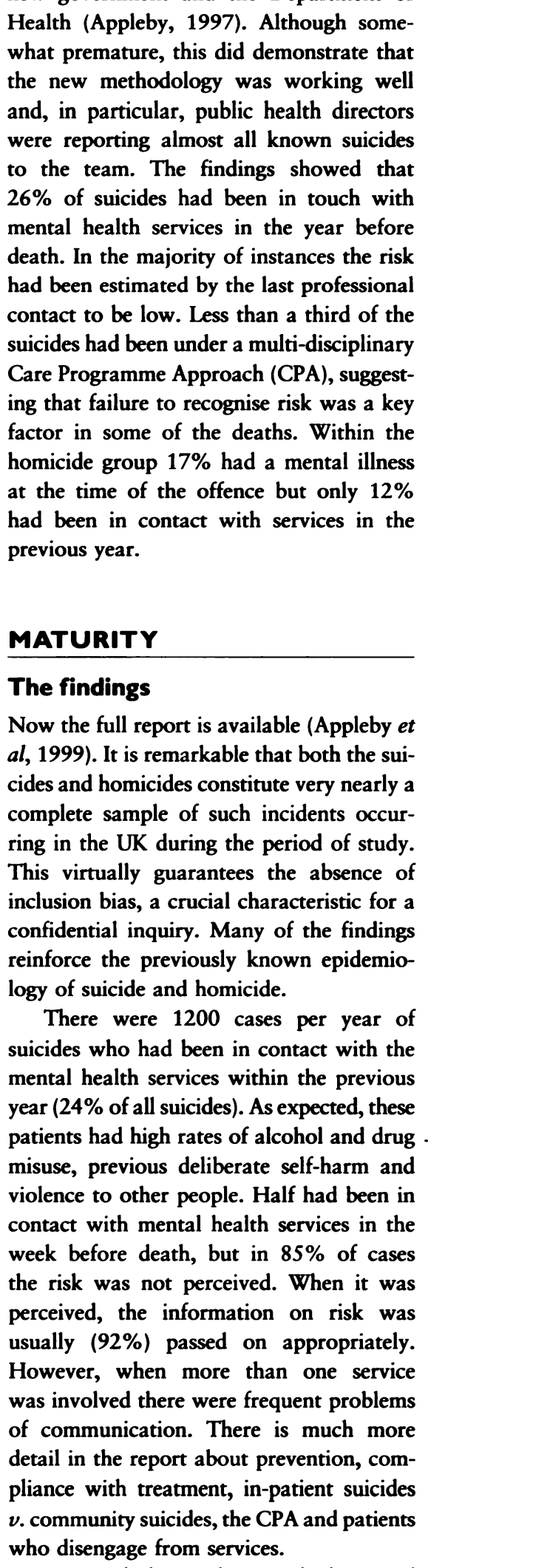

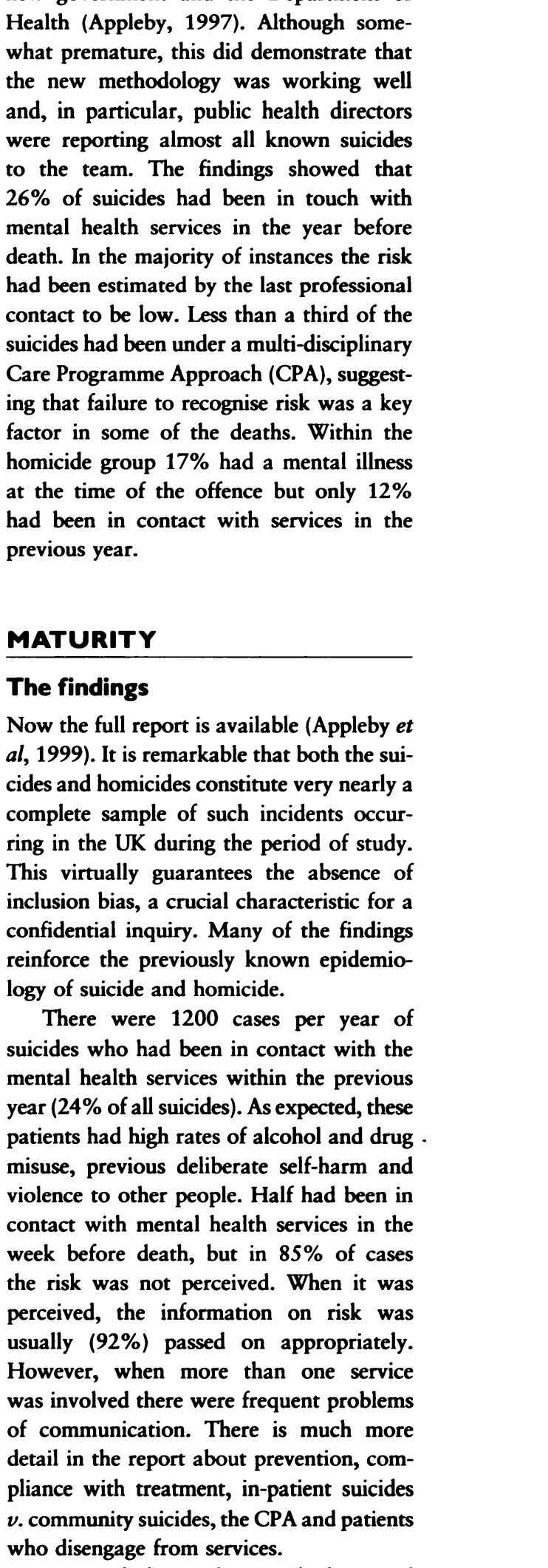

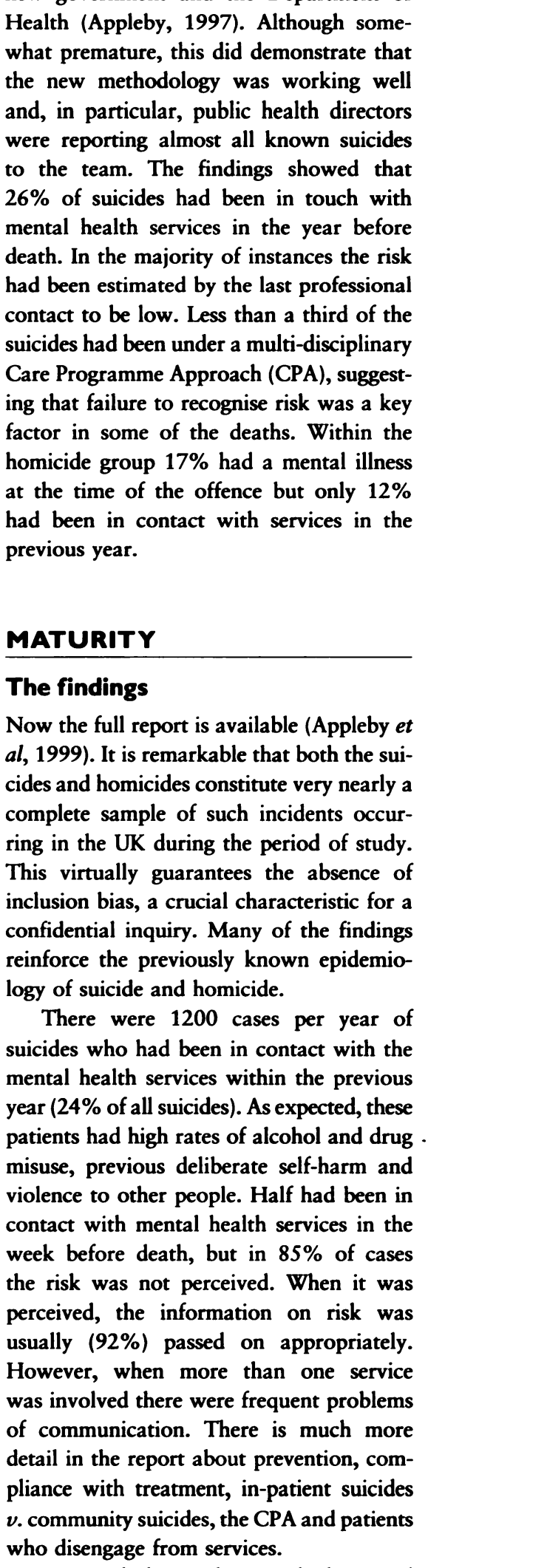

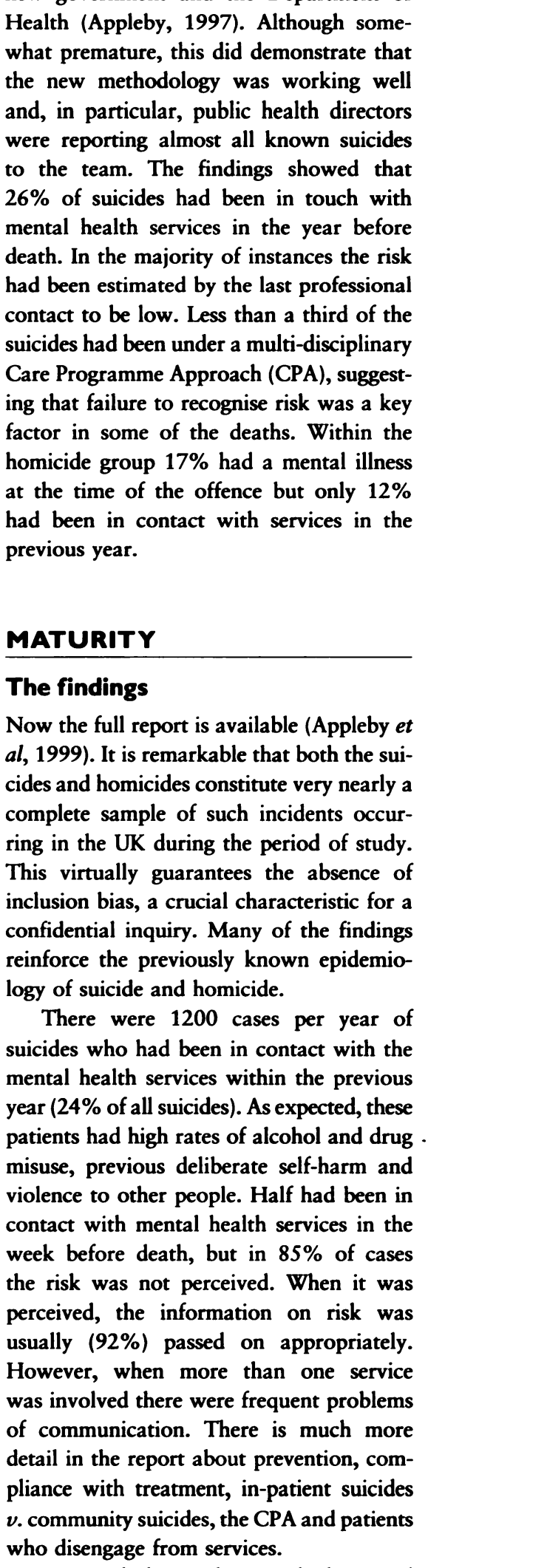

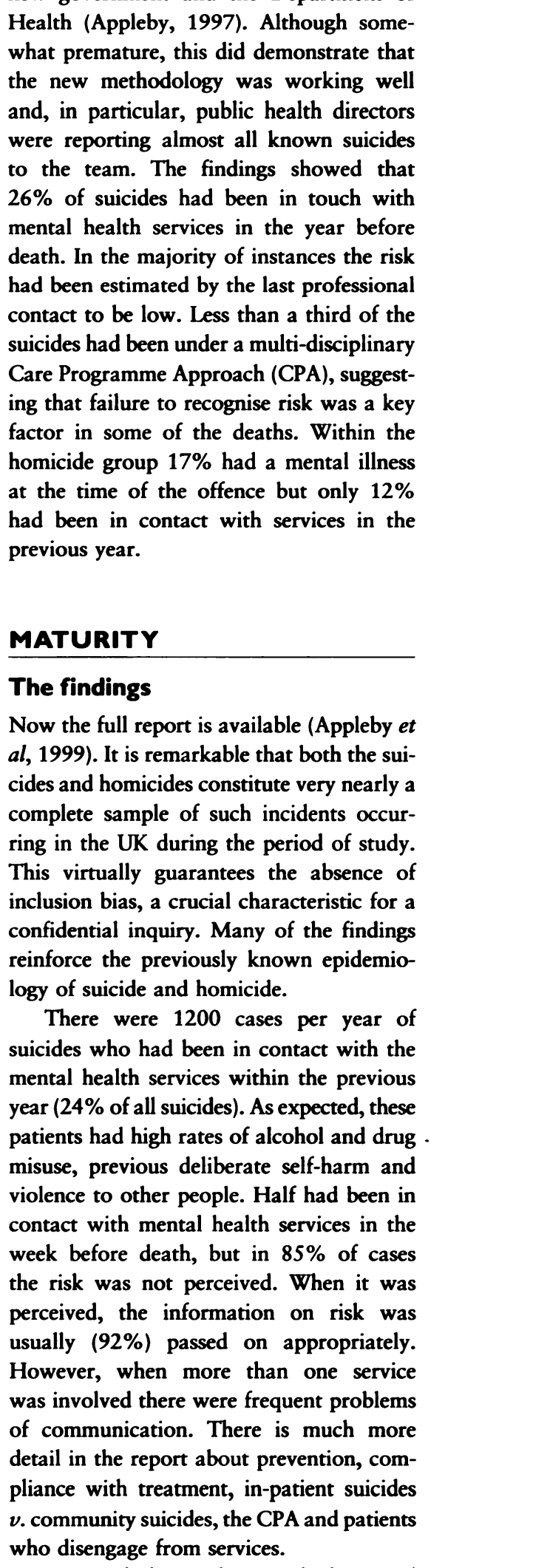

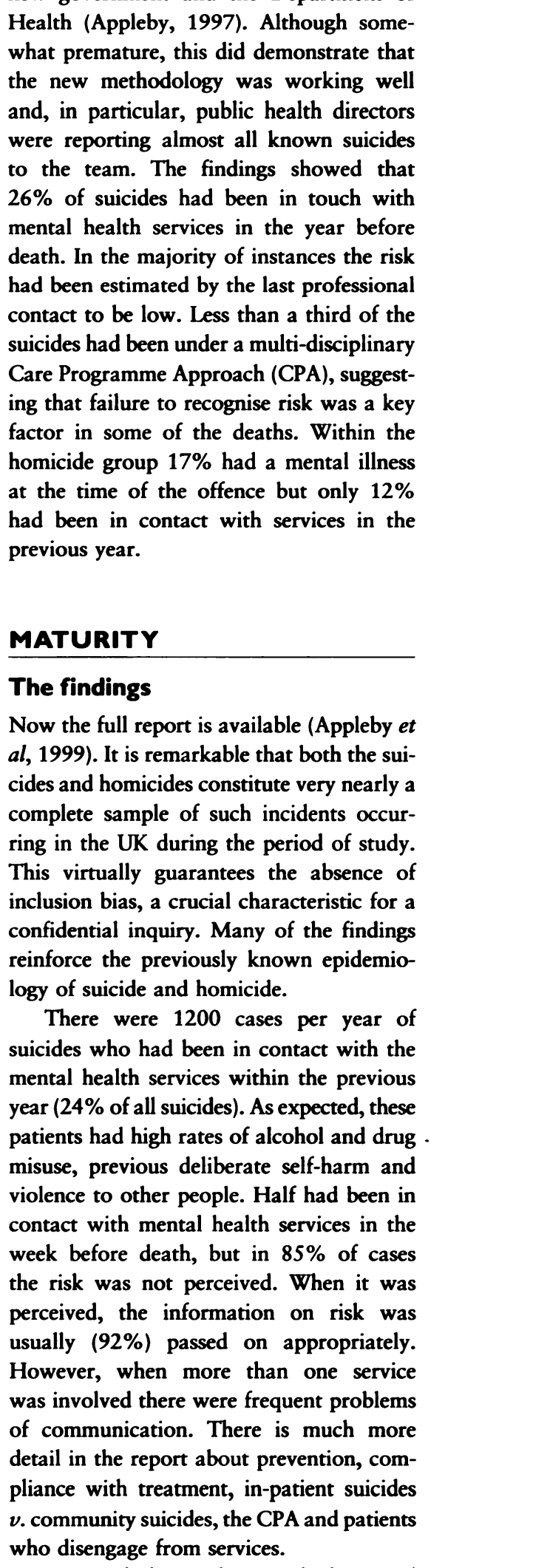

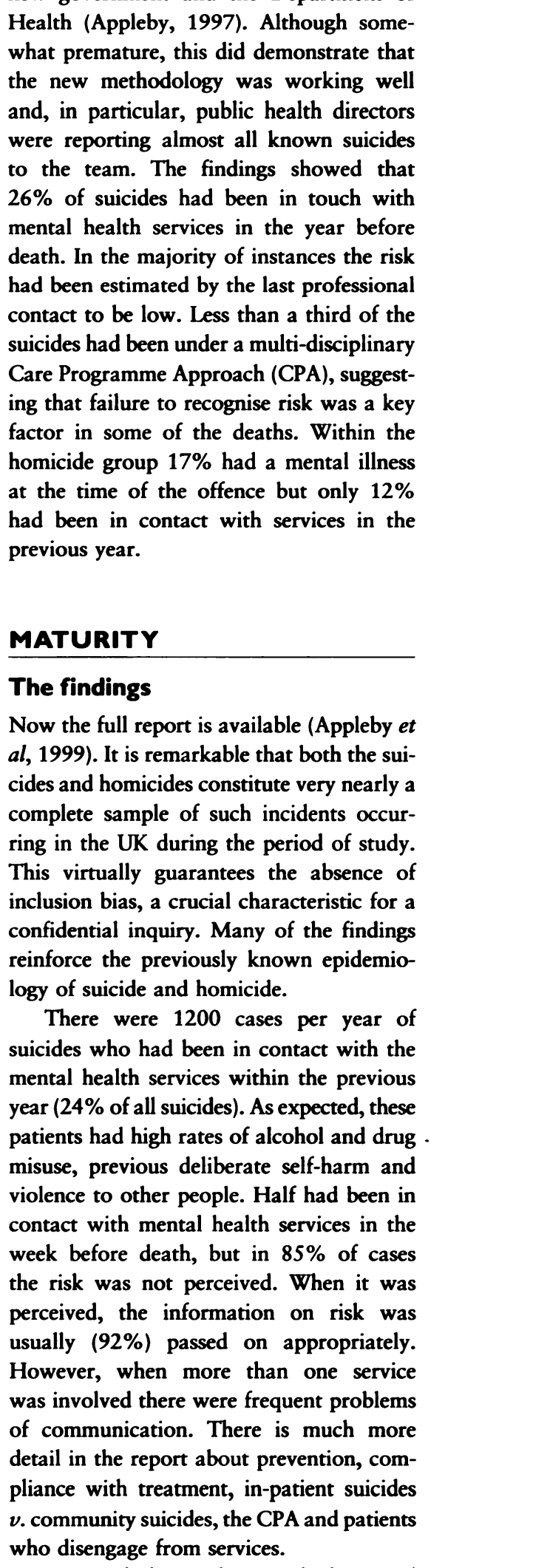

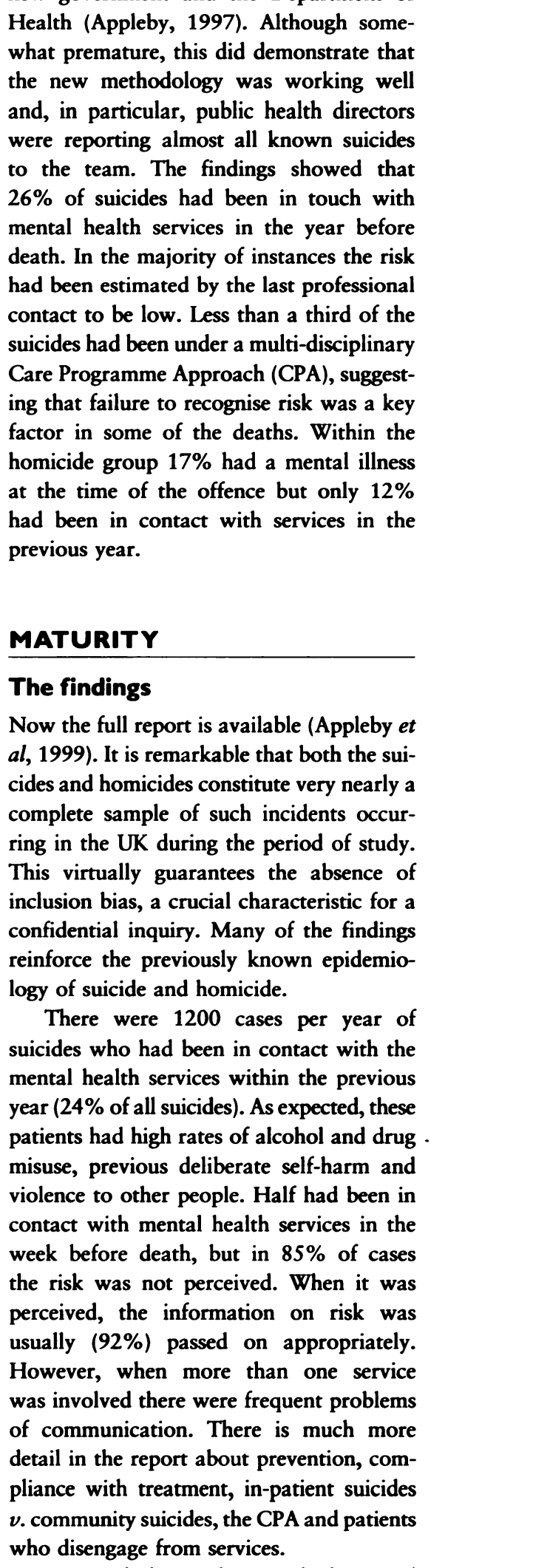

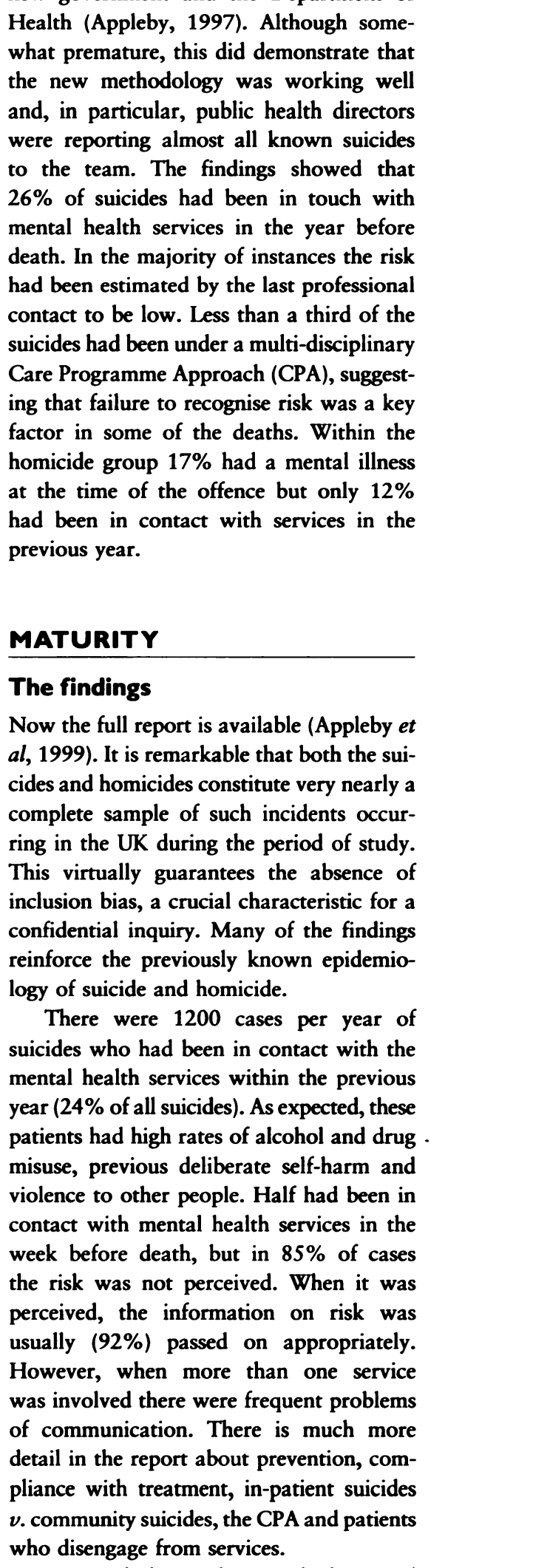

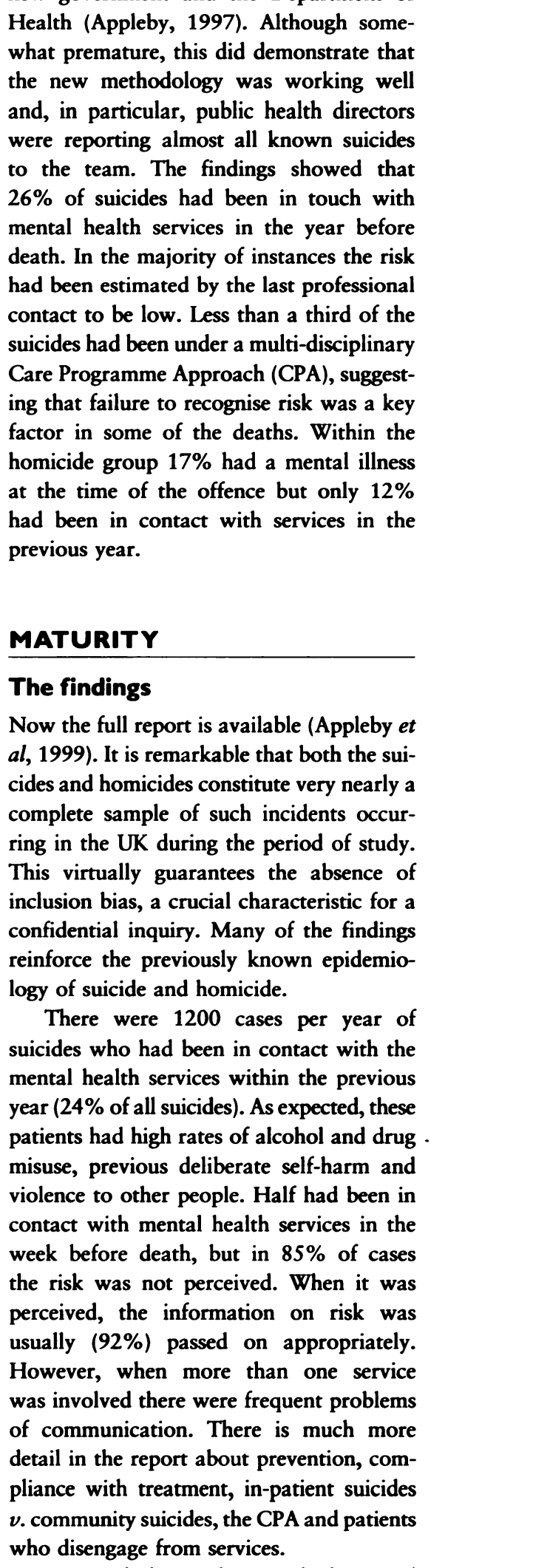

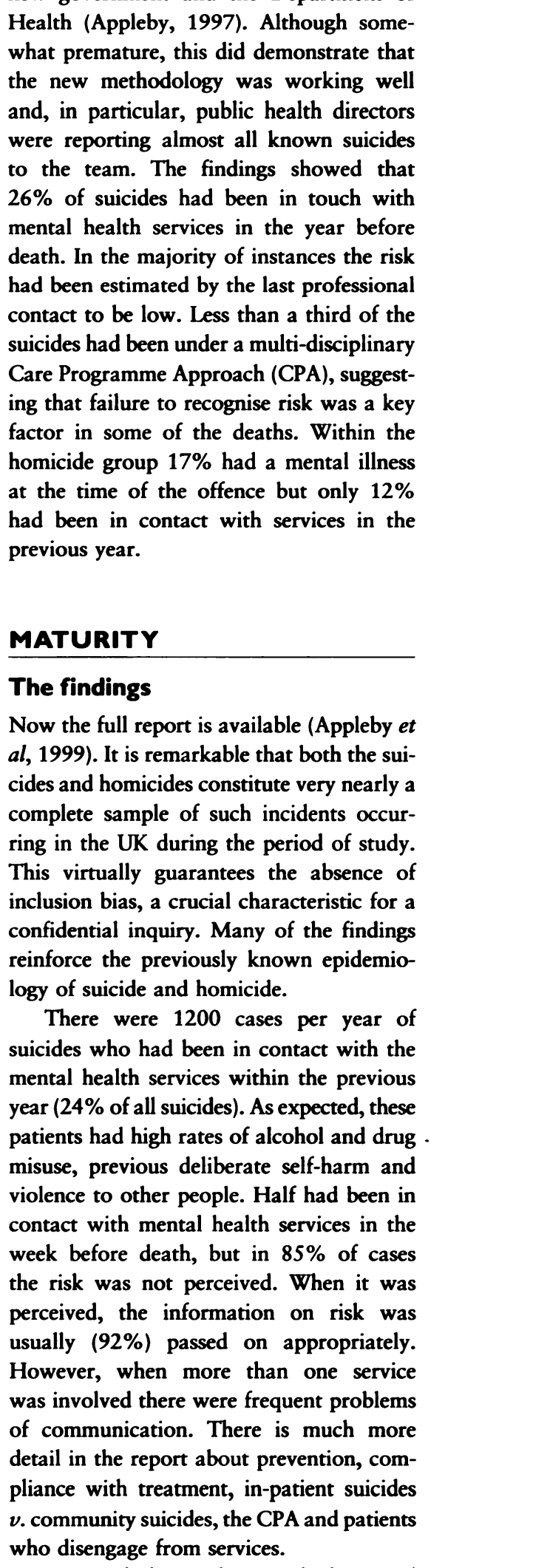

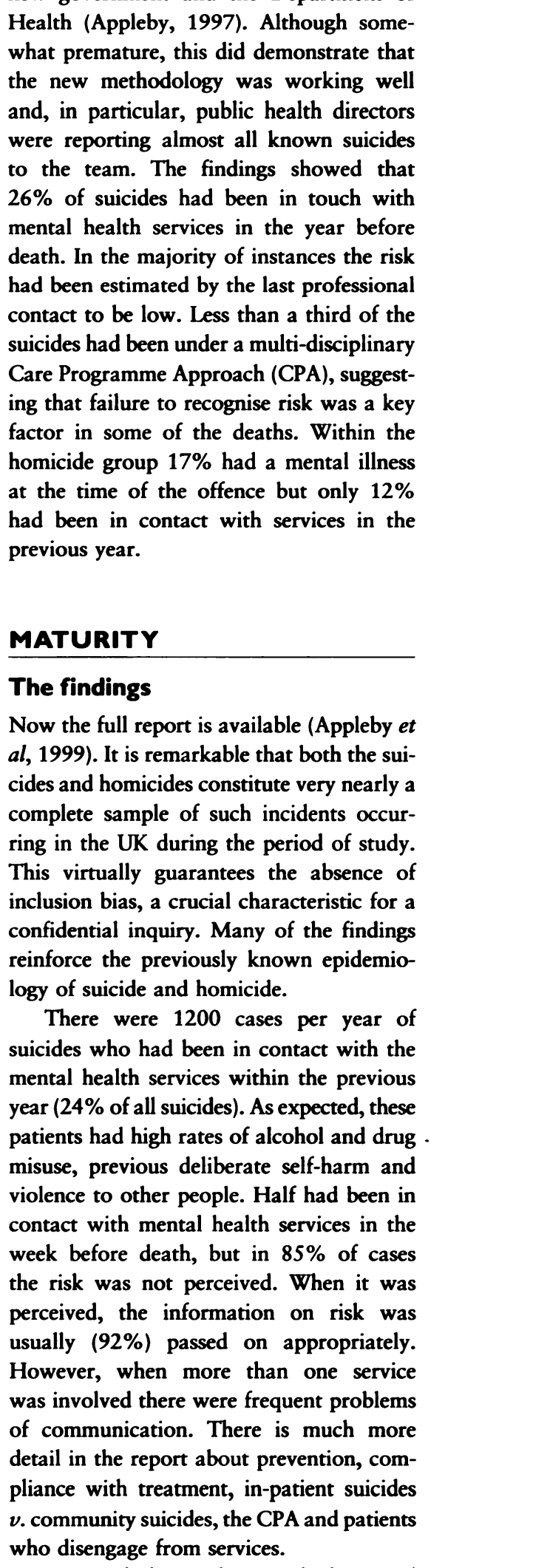

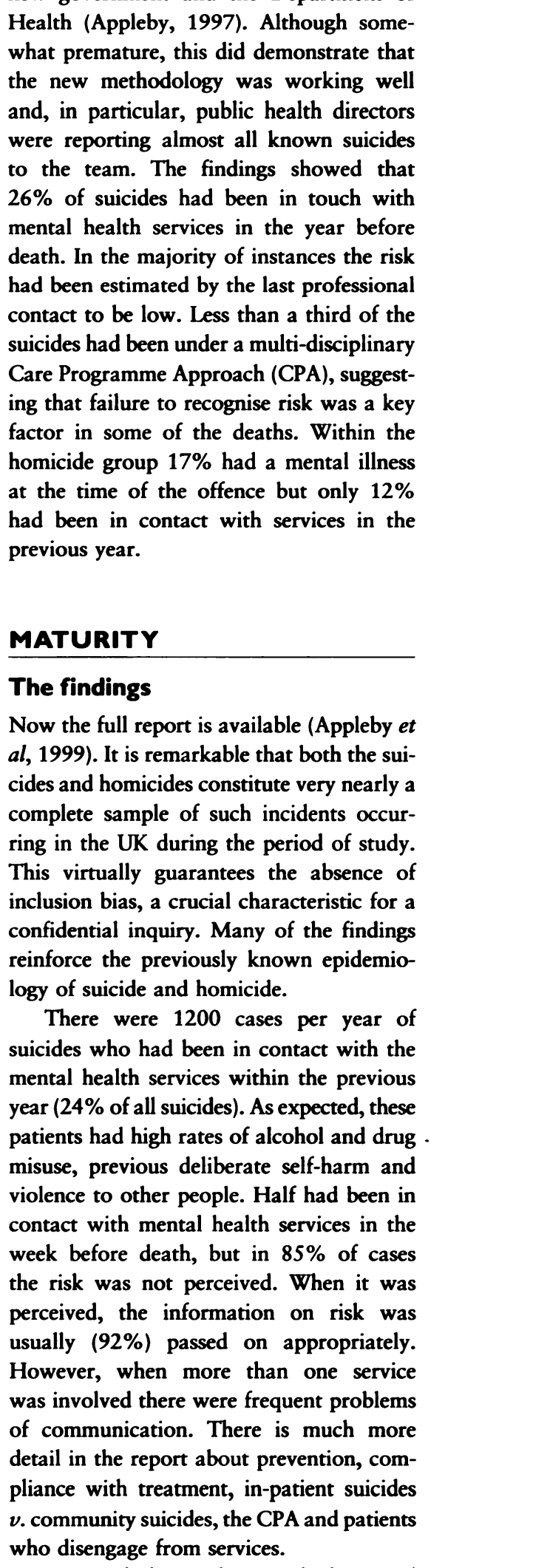

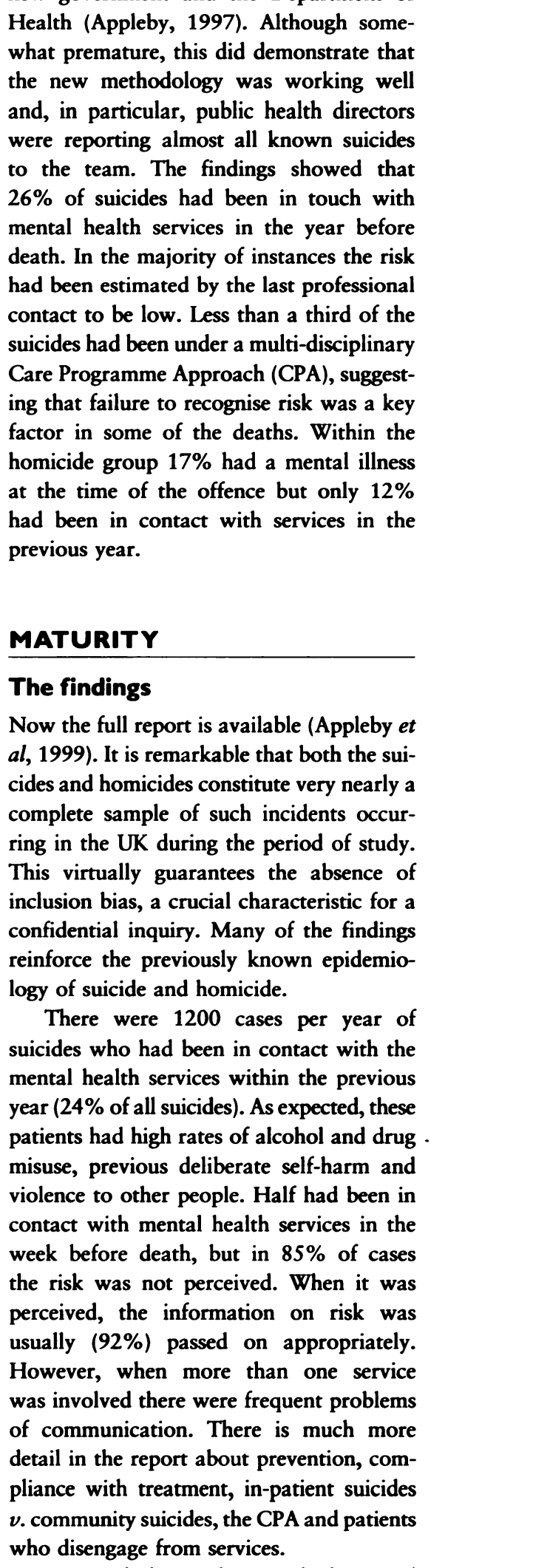

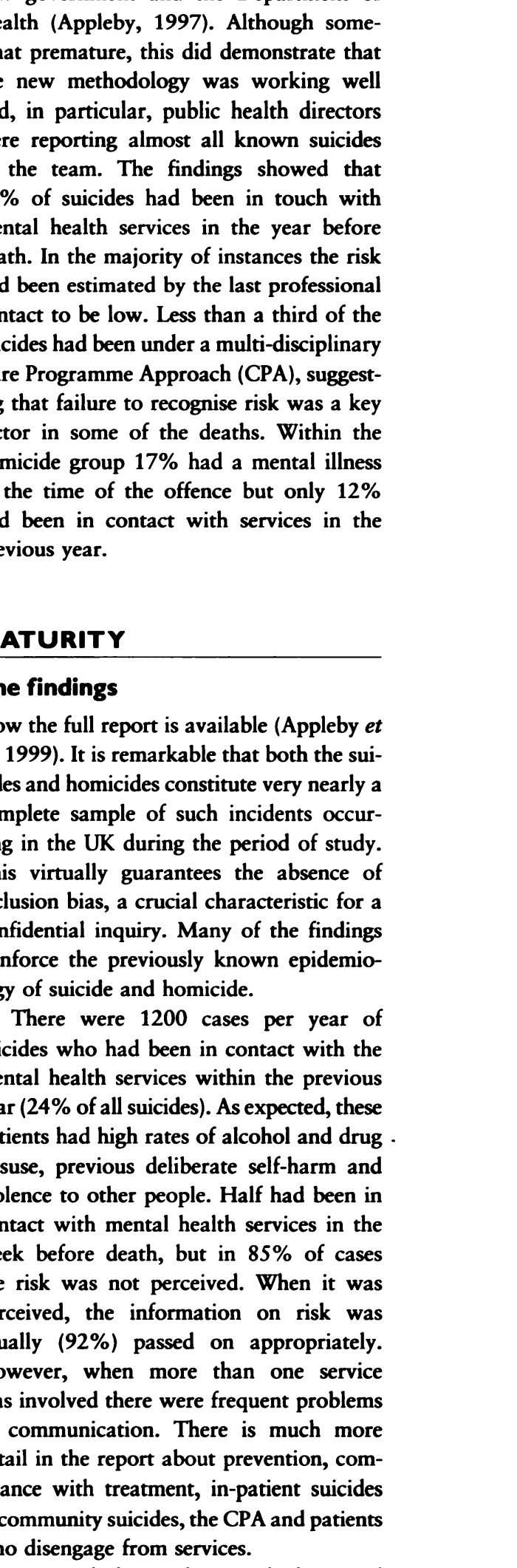

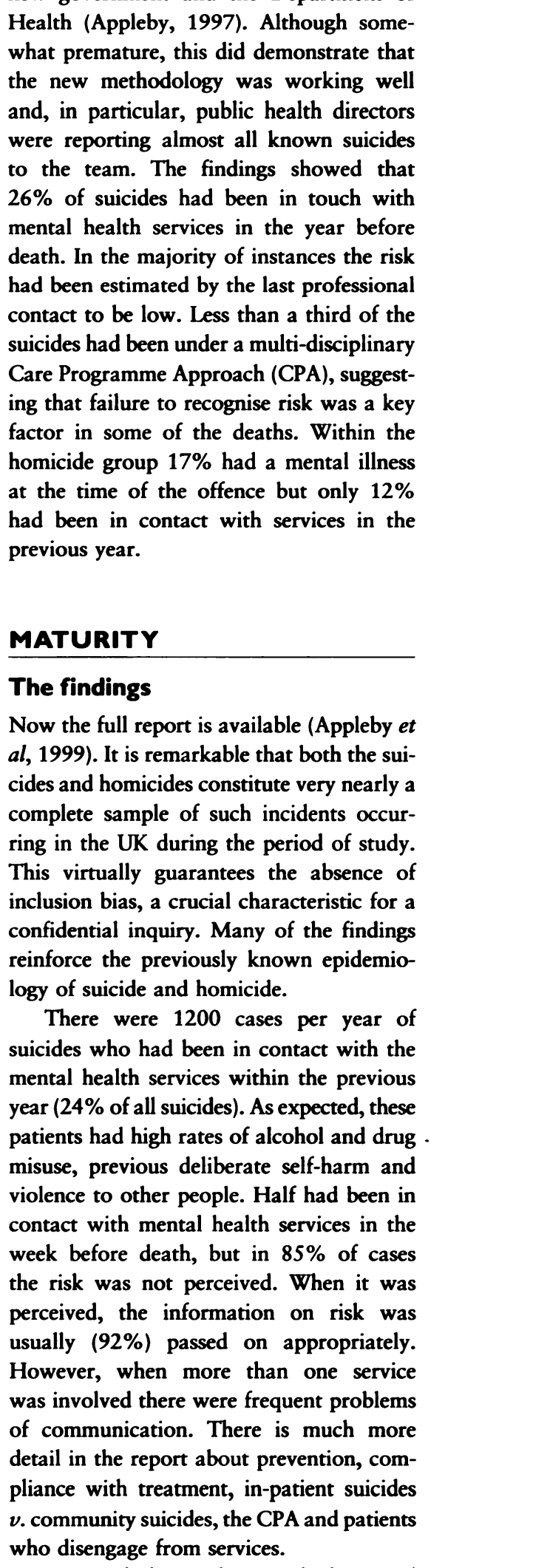

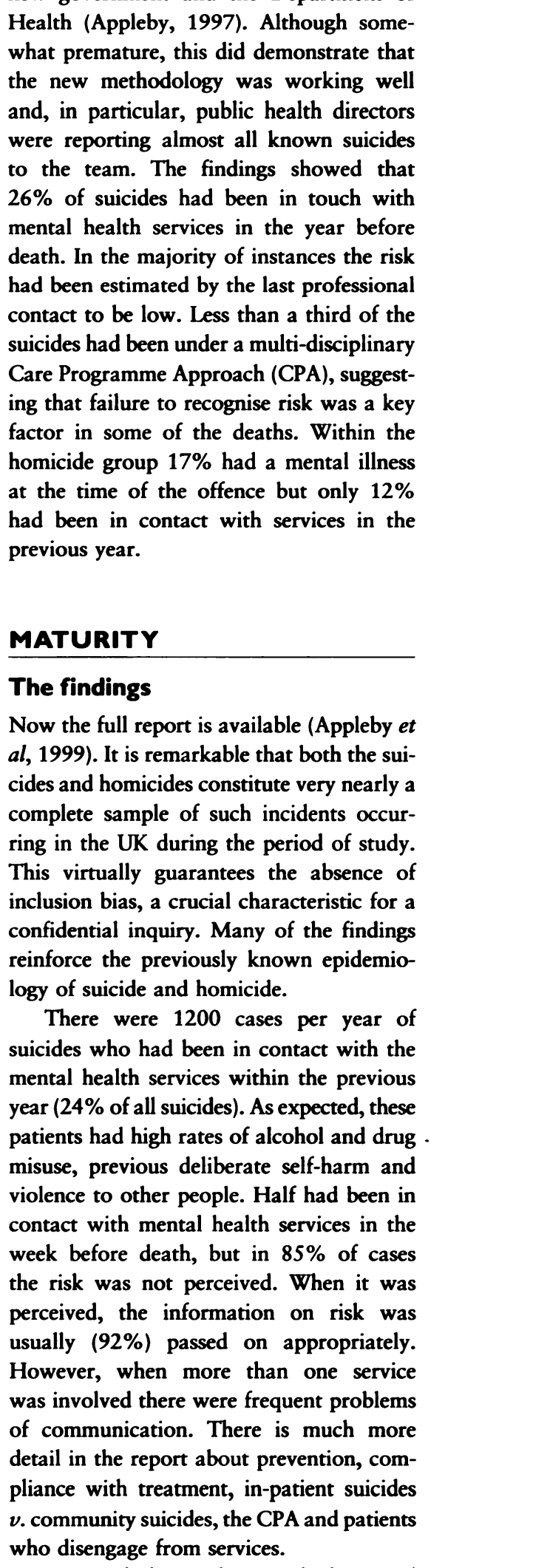

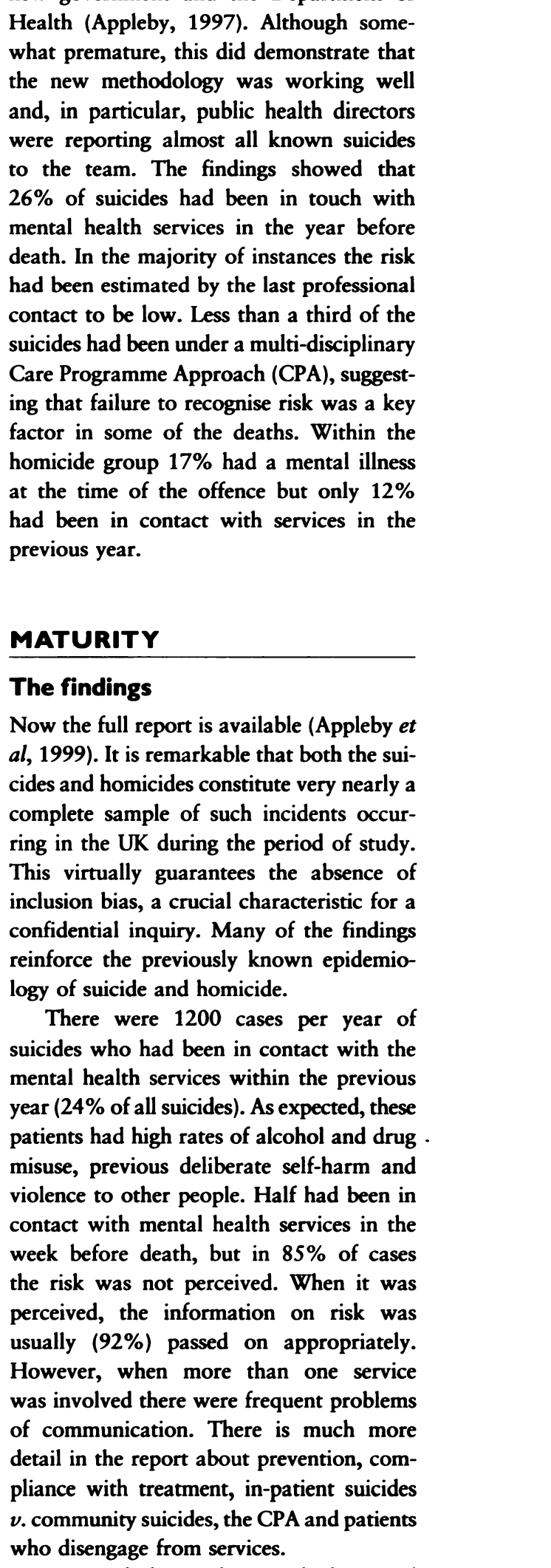

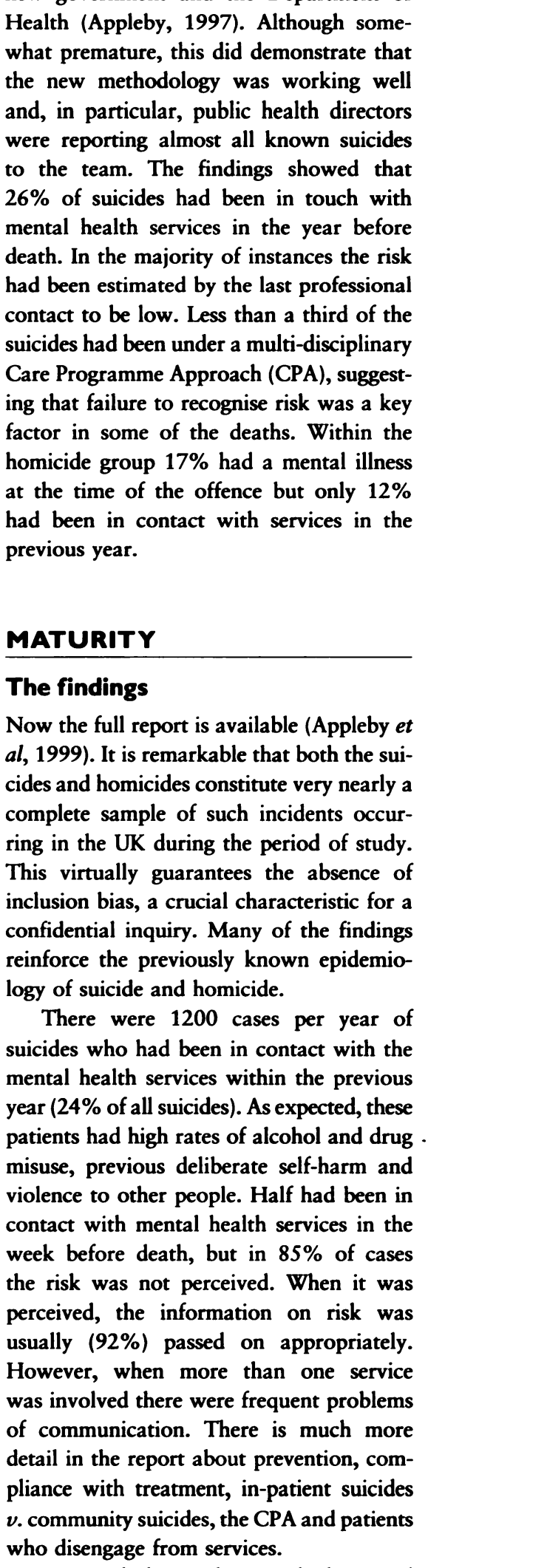

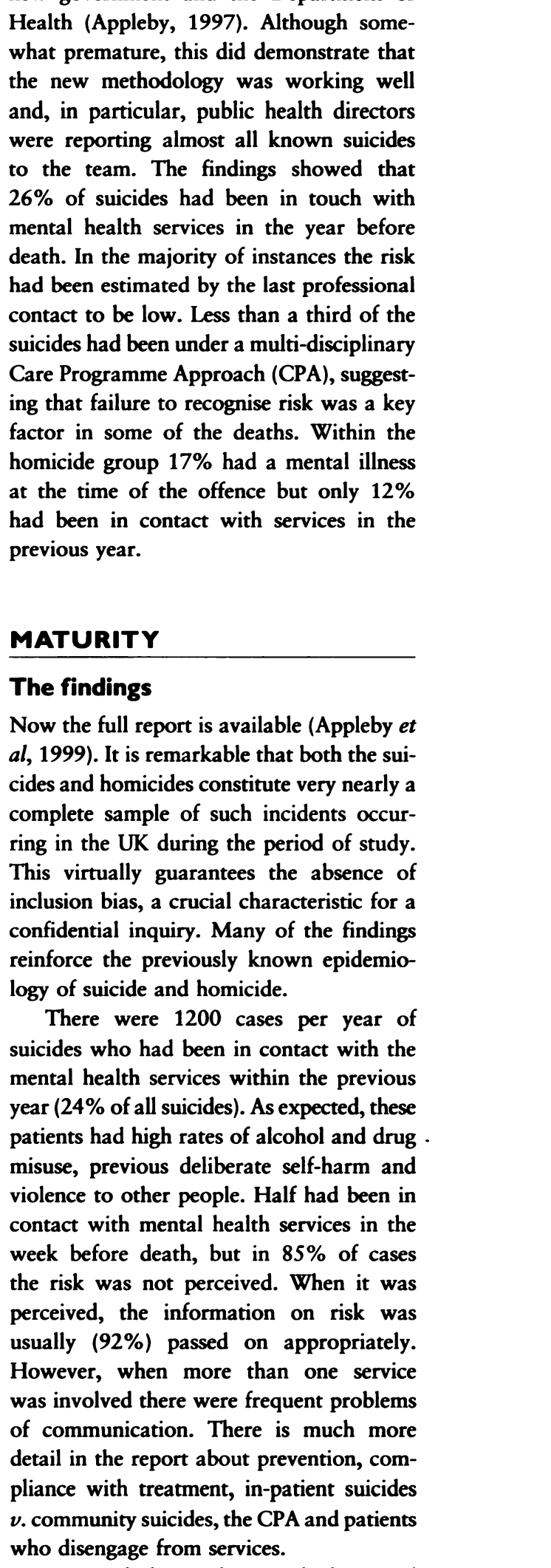

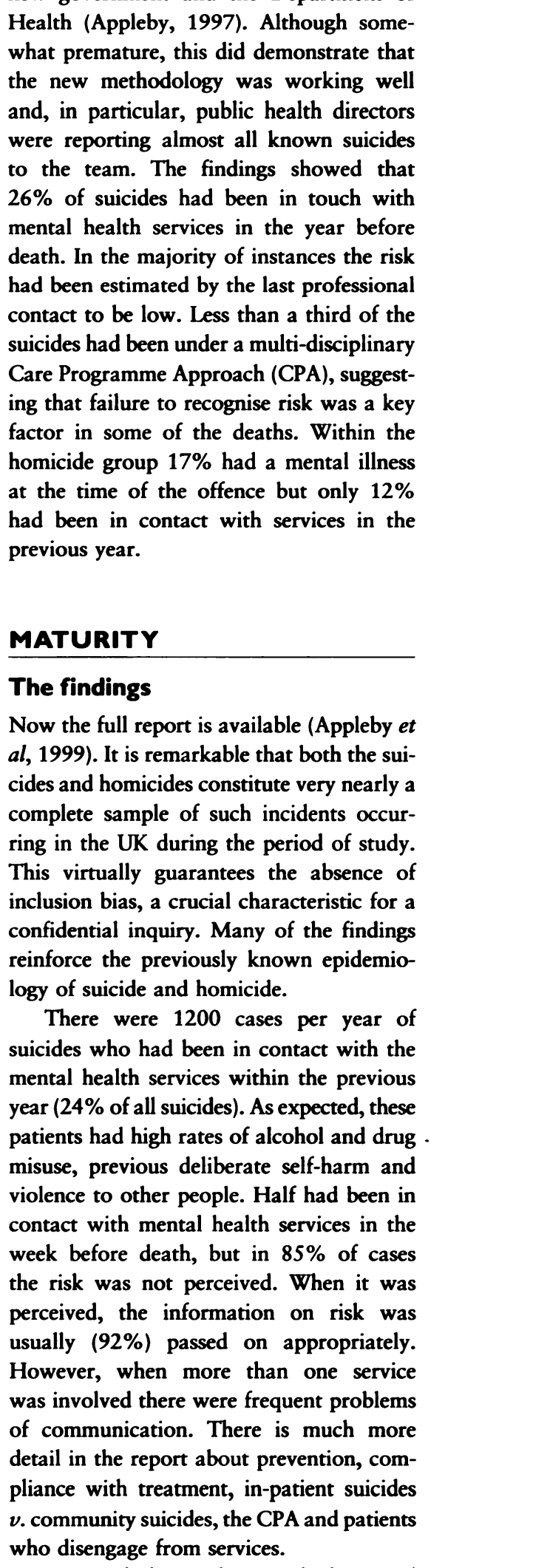

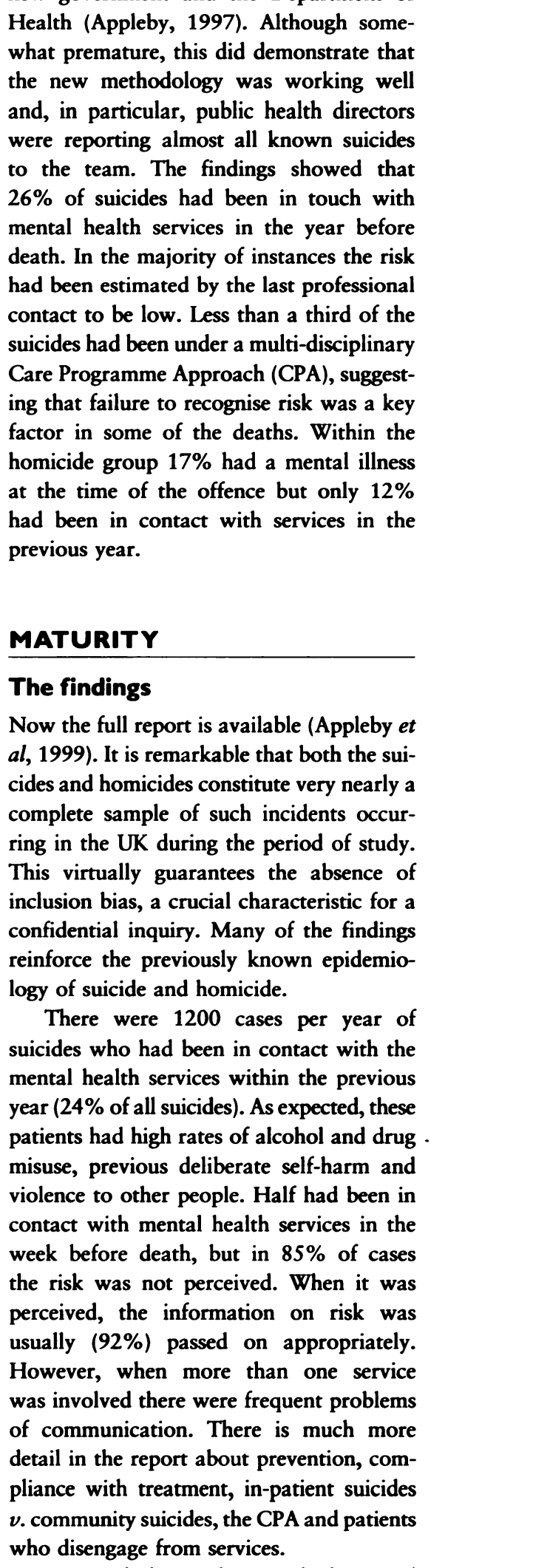

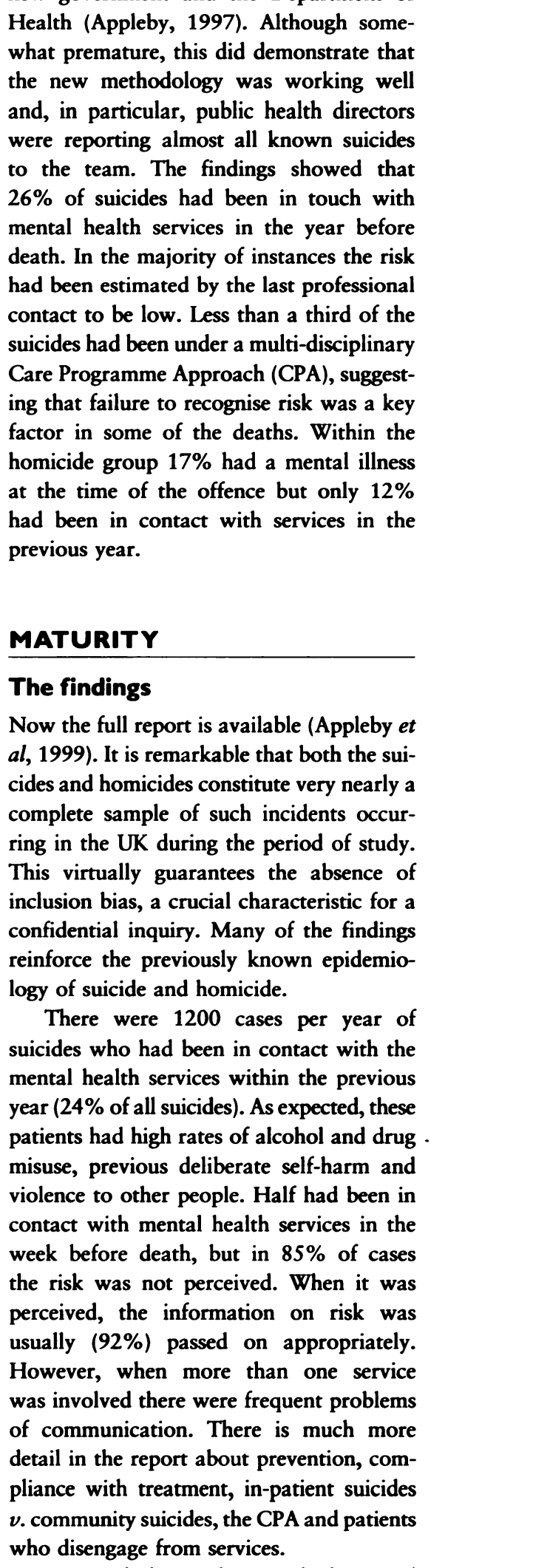

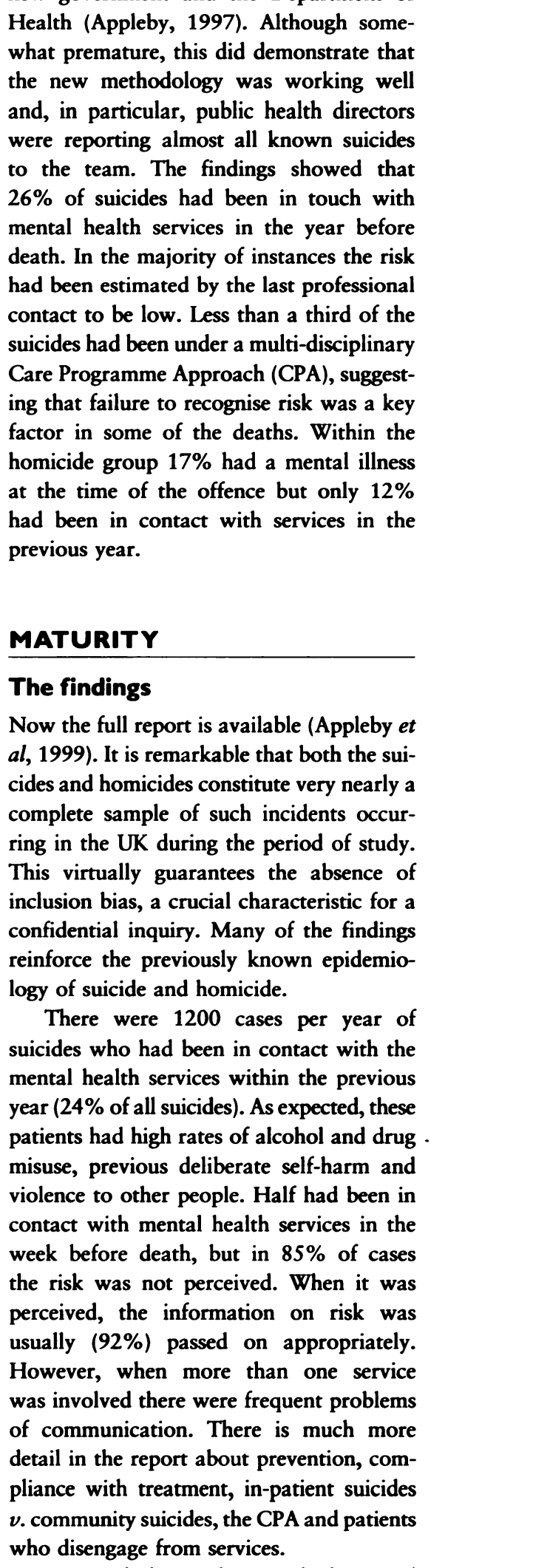

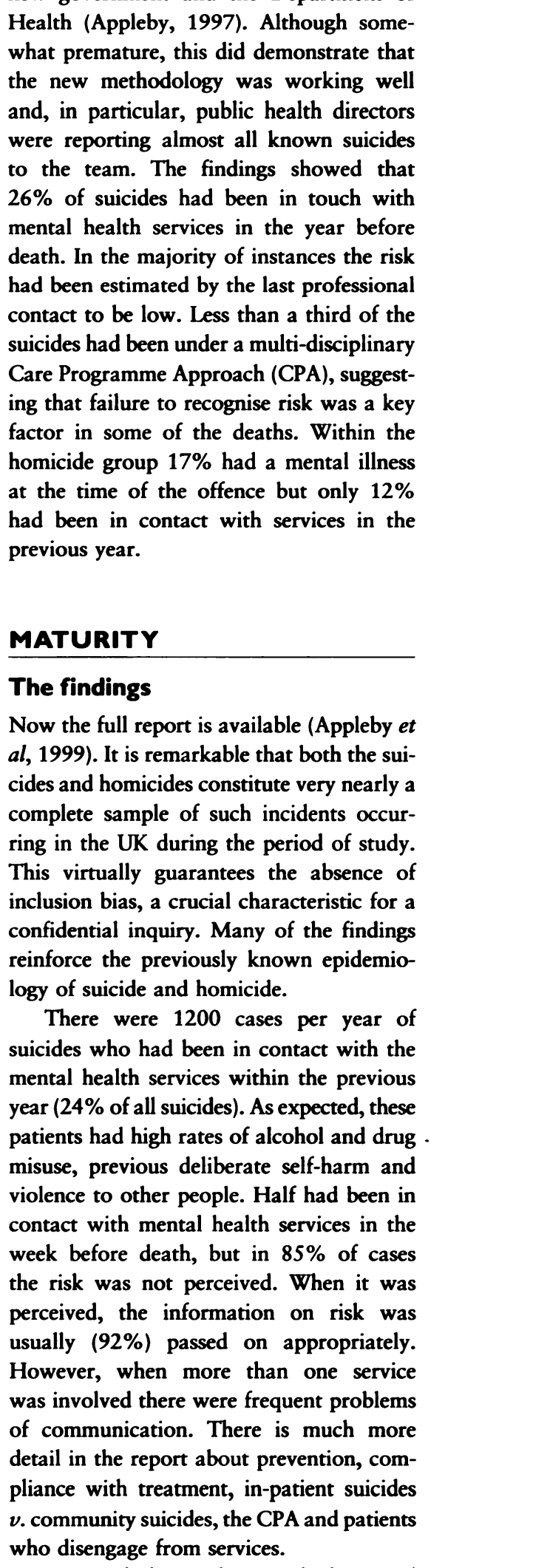

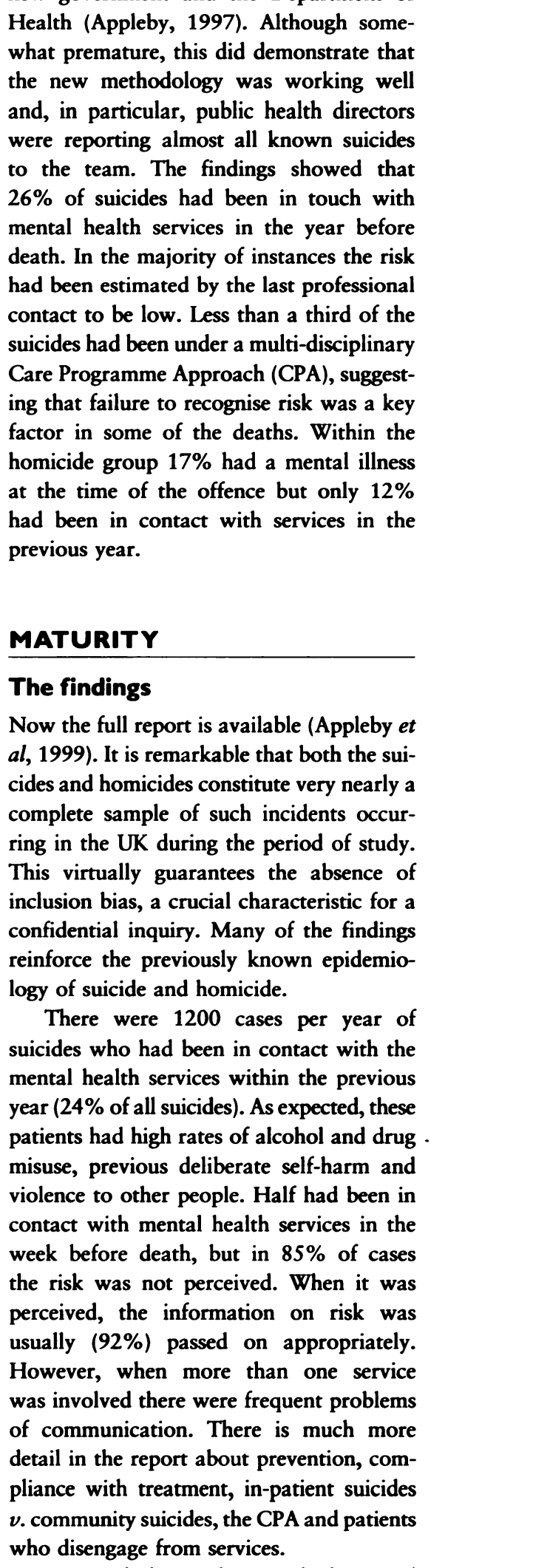

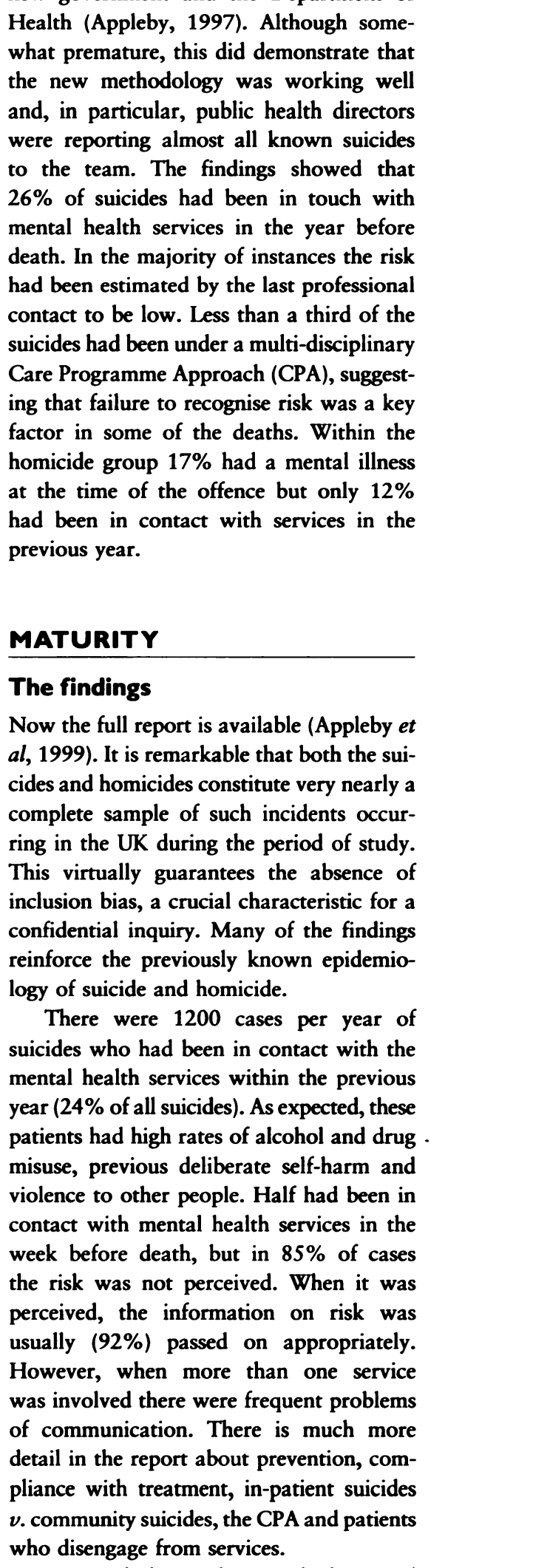

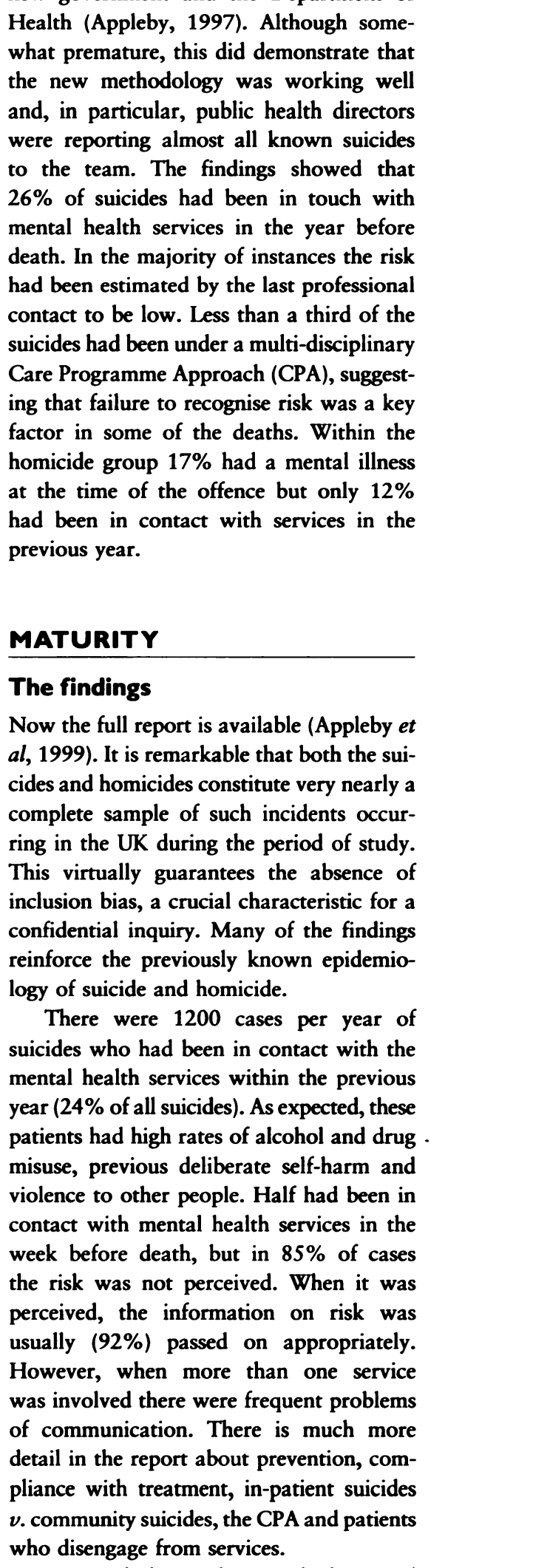

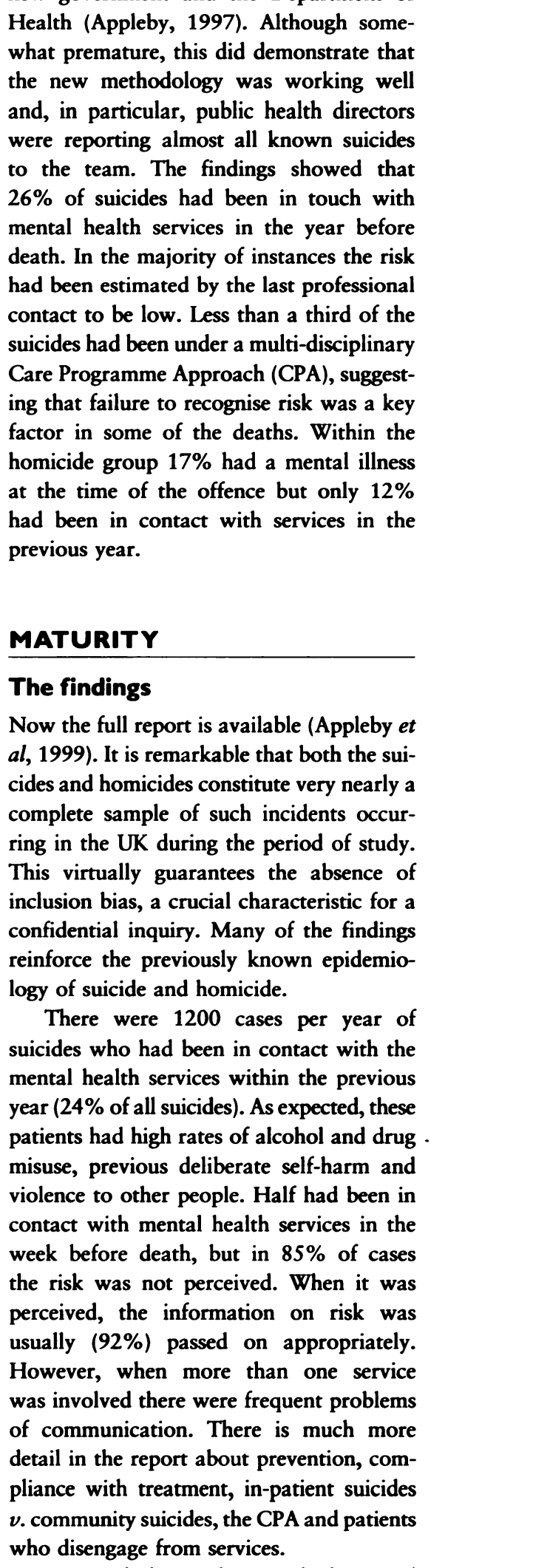

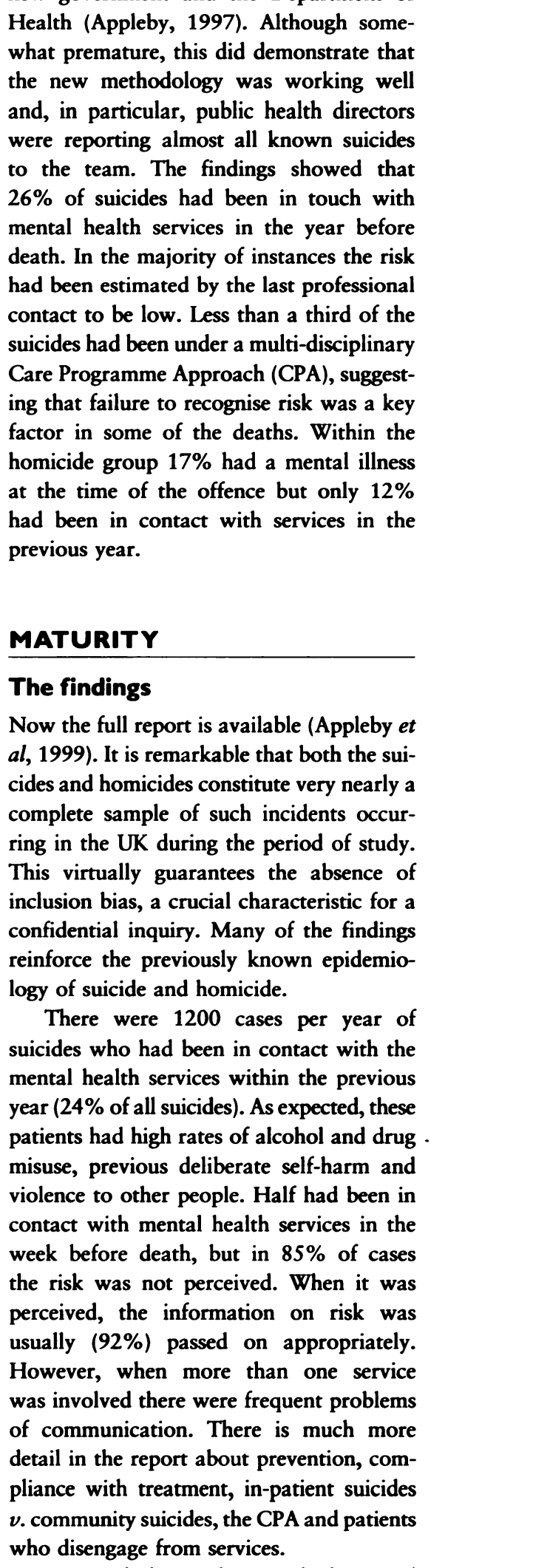

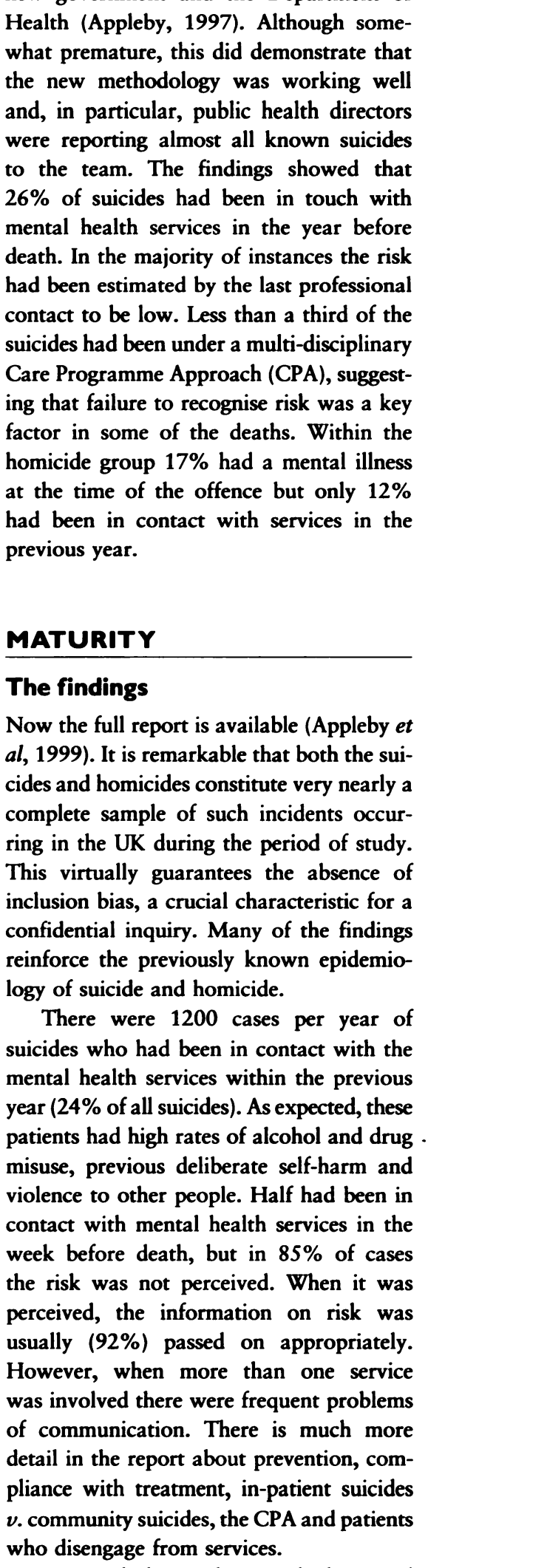

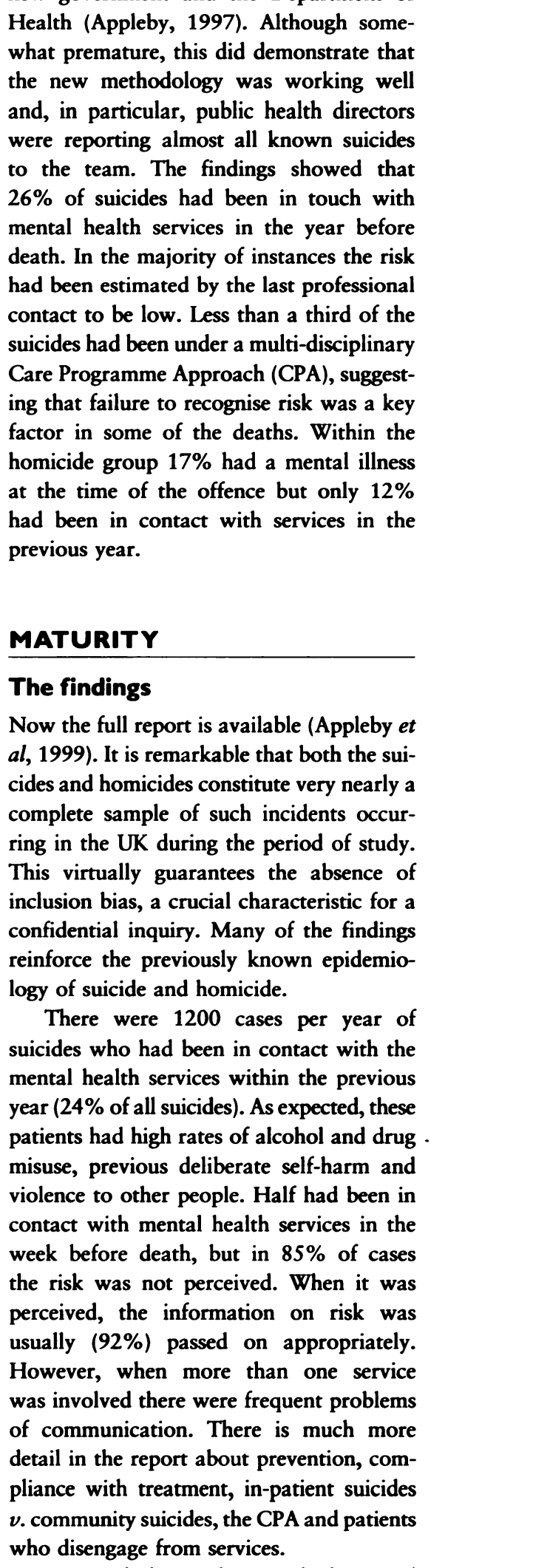

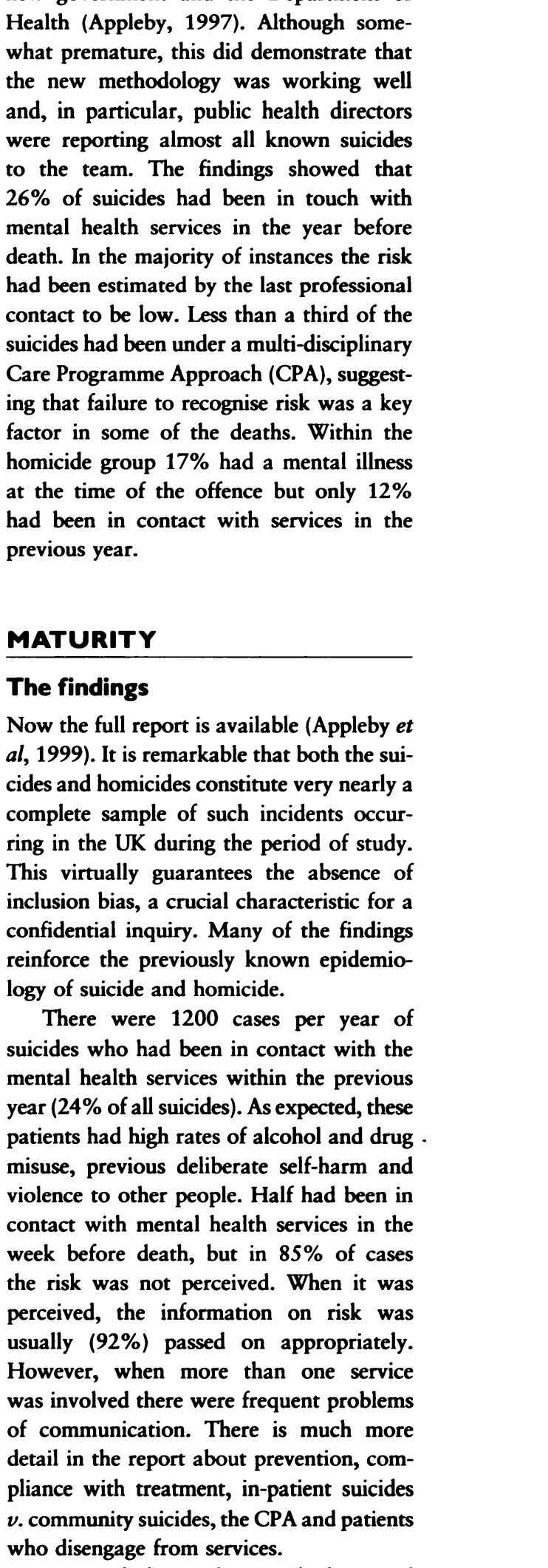
illness at the time of the offence. These were less likely than the non-mentally-ill group to have a record of violent offences and were more likely to have killed a family member than an unknown person. Eight 
per cent of all homicides had been in contact with mental health services in the year before the offence (about 40 cases a year). The majority had personality disorder with fewer having a diagnosis of schizophrenia. Alcohol and drug dependence were, of course, common and many had complex mental health needs with more than one diagnosis. Seventy-one per cent of those who had been in contact with services had lost contact, almost always through patient-initiated discharge, and $23 \%$ were non-compliant with medication. On the other hand, $14 \%$ had been in contact within the previous week. Once again there is a wealth of detail in the report that cannot easily be distilled into a brief editorial.

\section{The recommendations}

The report makes 31 recommendations, and the authors do not restrict themselves slavishly to following the data when a striking general picture emerges. For example, they recommend a thorough overhaul of the CPA to concentrate more on those at risk. They also recommend training in risk assessment for all mental health workers, the simplification of the administrative component of clinical care and the use of patient passports to carry information between services. Noncompliance emerges as a serious problem and the report recommends both the prescription of newer psychotropic drugs and the creation of new legal powers. Changes to the structure of some in-patient wards will be necessary if the number of in-patient suicides is to be reduced. Assertive outreach and the integration of alcohol and drug services with general psychiatry are among the far-reaching recommendations on clinical care. Psychiatrists will want to read and assess these recommendations for themselves. Many of them reinforce what the profession has been advocating for some time, but go beyond the formulaic concerns about resources and community $v$. hospital care which have characterised both the professional and public debates.

CHRIS THOMPSON, FRCPsych, Royal South Hants Hospital, Brinton's Terrace, Southampton SOI4 OYG

(First received 20 April 1999, final revision 3 June 1999, accepted 3 June 1999)

The findings are sobering and the recommendations are well considered. They should leave no room for exploitation by demagogues on either side of the community care debate. They transcend the reasons for which the Inquiry was originally set up, by addressing both broader and deeper issues than just 'failures of community care'. For that reason the funding of the Inquiry must continue, albeit as part of the National Institute for Clinical Excellence (NICE).

\section{The wider context}

This report has, however, a more farreaching significance for psychiatry. In a professional perspective it places psychiatric services alongside high-status specialities such as surgery, obstetrics and paediatrics that also have confidential inquiries. These inquiries exist because it is recognised that there are some circumstances in which disasters can occur during the process of clinical care. In all cases the other inquiries have made recommendations from their findings that have led to reduced death rates from complications that were previously poorly understood. It is to be hoped that the same will be true of our Inquiry.

From an international perspective the view is even more striking. No other government anywhere in the world has taken the deaths of psychiatric patients so seriously. Therefore, there is no equivalent in any other country. No national psychiatric organisation other than the Royal College of Psychiatrists has cooperated so extensively with an in-depth investigation of psychiatry's 'failures' - reflecting the unique charter and standing of the College. As a result of this synergy between government and profession (at a difficult time in their relationship) this country has taken the lead in efforts to reduce the unnecessary toll of deaths in mentally ill people and their relatives. Psychiatrists will no doubt continue to provide the Inquiry with the data it needs to track changes in the national picture. The Department of Health must commit itself to continuing the funding of the Inquiry until it has demonstrated that new initiatives are working to the benefit of these vulnerable patients.

So the government, the profession and the team at the Confidential Inquiry can rightly be proud of what has already been achieved. However, one must acknowledge that a confidential inquiry method cannot answer all the important questions. Different approaches are necessary to identify the relative risk posed by each of the factors that have been shown to occur commonly in critical incidents. For example, case-control studies could show the relative risk attached to, say, a previous history of self-harm in particular high-risk situations - such as at the point of discharge from hospital. Combining these estimates with the absolute frequencies of risk factors occurring in the national suicide group will be a further, fruitful addition to our knowledge. This should then allow the training of front-line staff to carry out more precise risk assessments, which may, in turn, reduce the numbers of suicides and homicides.

\section{REFERENCES}

Appleby, L. (1997) Progress Report, National Confidential Inquiry into Suicide and Homicide by People with a Mental IIIness. London: Department of Health.

_, Shaw, J., Amos, T., et al (1999) Safer Services: Report of the National Confidential Inquiry into Suicide and Homicide by People with a Mental IIIness. London: Department of Health.

Boyd, W. (1994) A Preliminary Report on Homicide. London: Confidential Inquiry into Homicides and Suicides by Mentally III People. 